Article

\title{
Synthesis and Antiplasmodial Evaluation of 4-Carboxamido- and 4-Alkoxy-2-Trichloromethyl Quinazolines
}

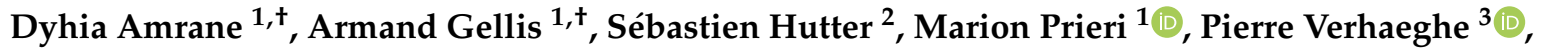 \\ Nadine Azas ${ }^{2}$, Patrice Vanelle ${ }^{1, *}$ and Nicolas Primas ${ }^{1, *}$ \\ 1 Aix Marseille Univ, CNRS, ICR UMR 7273, Equipe Pharmaco-Chimie Radicalaire, Faculté de Pharmacie, \\ 13385 Marseille CEDEX 05, France; dyhia.amrane@etu.univ-amu.fr (D.A.); \\ armand.gellis@univ-amu.fr (A.G.); Marion.Prieri@newcastle.ac.uk (M.P.) \\ 2 IHU Méditerranée Infection, UMR VITROME, IRD, SSA, Mycology \& Tropical Eucaryotic Pathogens, \\ Aix Marseille Univ, 13005 Marseille CEDEX 05, France; sebastien.hutter@univ-amu.fr (S.H.); \\ nadine.azas@univ-amu.fr (N.A.) \\ 3 LCC-CNRS Université de Toulouse, CNRS, UPS, 31400 Toulouse, France; pierre.verhaeghe@lcc-toulouse.fr \\ * Correspondence: patrice.vanelle@univ-amu.fr (P.V.); nicolas.primas@univ-amu.fr (N.P.) \\ + These authors contributed equally to this work.
}

Academic Editor: Branka Zorc

Received: 31 July 2020; Accepted: 26 August 2020; Published: 27 August 2020

\begin{abstract}
From three previously identified antiplasmodial hit compounds $(\mathrm{A}-\mathrm{C})$ and inactive series (D), all based on a 2-trichloromethylquinazoline scaffold, we conducted a structure-activity relationship (SAR) study at position four of the quinazoline ring by synthesizing 42 novel derivatives bearing either a carboxamido- or an alkoxy-group, to identify antiplasmodial compounds and to enrich the knowledge about the 2-trichloromethylquinazoline antiplasmodial pharmacophore. All compounds were evaluated in vitro for their cytotoxicity towards the HepG2 cell line and their activity against the multiresistant $\mathrm{K} 1 P$. falciparum strain, using doxorubicin, chloroquine and doxycycline as reference drugs. Four hit-compounds $\left(\mathrm{EC}_{50} \mathrm{~K} 1\right.$ P. falciparum $\leq 2 \mu \mathrm{M}$ and $\left.\mathrm{SI} \geq 20\right)$ were identified among 4-carboxamido derivatives $(\mathbf{2}, \mathbf{9}, \mathbf{1 6}$, and 24$)$ and two among 4-alkoxy derivatives (41 and 44). Regarding the two most potent molecules (16 and 41), five derivatives without a 2-CCl group were prepared, evaluated, and appeared totally inactive $\left(\mathrm{EC}_{50}>50 \mu \mathrm{M}\right)$, showing that the 2-trichloromethyl group was mandatory for the antiplasmodial activity.
\end{abstract}

Keywords: 2-trichloromethylquinazoline; Plasmodium falciparum; in vitro HepG2 cytotoxicity; structure-activity relationships

\section{Introduction}

Among parasitic diseases, malaria remains the leading cause of death in 2020. According to the World Malaria Report 2019 [1], some 405,000 deaths were reported in 2018 for 228 million cases of malaria worldwide. Children under five years old are the most vulnerable group, accounting for $67 \%$ of the deaths. Malaria in humans is caused by five different species of Plasmodium protozoa, among which, P. falciparum is by far the most lethal, mainly in Africa. P. vivax, responsible for relapses, is mainly found in South-East Asia. The parasites are vectorized during blood-meal by infected female mosquitoes belonging to the Anopheles genus. Huge efforts have been made to control and eradicate the disease, leading to a significant reduction in the number of deaths, from 585,000 in 2010 to 405,000 in 2018 [1]. Despite this improvement, the emergence of forms of resistance to the first line treatments recommended by the $\mathrm{WHO}$, the artemisinin-combination therapies (ACT), currently threaten efforts to control the disease. PfKelch13 mutations have been identified as molecular markers of artemisinin resistance [2]. Recognized since 2002-2004, artemisinin resistance was originally located mainly in the 
Greater Mekong Subarea [3], and failure rates for first-line ACTs were found to be as high as 93\% in Thailand [1]. However, the emergence of potential artemisinin-resistance PfKelch13 mutations was reported in African regions, leading to a major concern [4]. Thus, research efforts need to be pursued with a view to discovering new chemical entities with new mechanisms of action against Plasmodium.

Among small molecules displaying antiplasmodial activity, febrifugine (Figure 1), extracted from Dichroa febrifuga, is a natural alkaloid containing a quinazoline scaffold [5].<smiles>O=C(CC1NCCCC1O)Cn1cnc2ccccc2c1=O</smiles>

Figure 1. Structure of natural quinazoline-containing febrifugine.

Our group, dedicated to the development of a new antiplasmodial [6-8], previously described the antiplasmodial activity of 4-aryl-2-trichloromethylquinazoline derivatives [9]. Indeed, 4-(4'-fluorophenyl)-2-trichloromethylquinazoline A (Table 1) showed an efficacy concentration 50\% $\left(\mathrm{EC}_{50}\right)$ of $2.5 \mu \mathrm{M}$ against the chloroquino-resitant $\mathrm{K} 1$ strain of $P$. falciparum and a cytotoxicity concentration $50 \%\left(\mathrm{CC}_{50}\right)$ above $125 \mu \mathrm{M}$ toward the human HepG2 cell line, compared with chloroquine, doxycycline and doxorubicin used as reference drugs. Indeed, chloroquine and doxycycline were still in use for antimalarial chemoprophylaxis along with the association of atovaquone and proguanil. Introducing an oxygen atom as a linker between position four of the quinazoline moiety and the phenyl group led to a two-fold improvement in antiplasmodial activity for compound B (Table 1) [10]. To study the Structure-Activity Relationships (SAR) related to the nature of the linker, an atom of carbon was added to provide a two-atom linker in 4-benzyloxy-2-trichloromethylquinazoline derivatives [11]. The resulting modification did not improve antiplasmodial activity, as shown with compound $\mathbf{C}($ Table 1$)$. When introducing a sulfonamide linker, affording 4-arylsulfonamido-2-trichloromethylquinazoline derivatives [12], the activity against $P$. falciparum was lost despite a significant decrease of the cytotoxicity (Table 1).

Table 1. Structures and in vitro activities of previously described compounds A-C and series D.

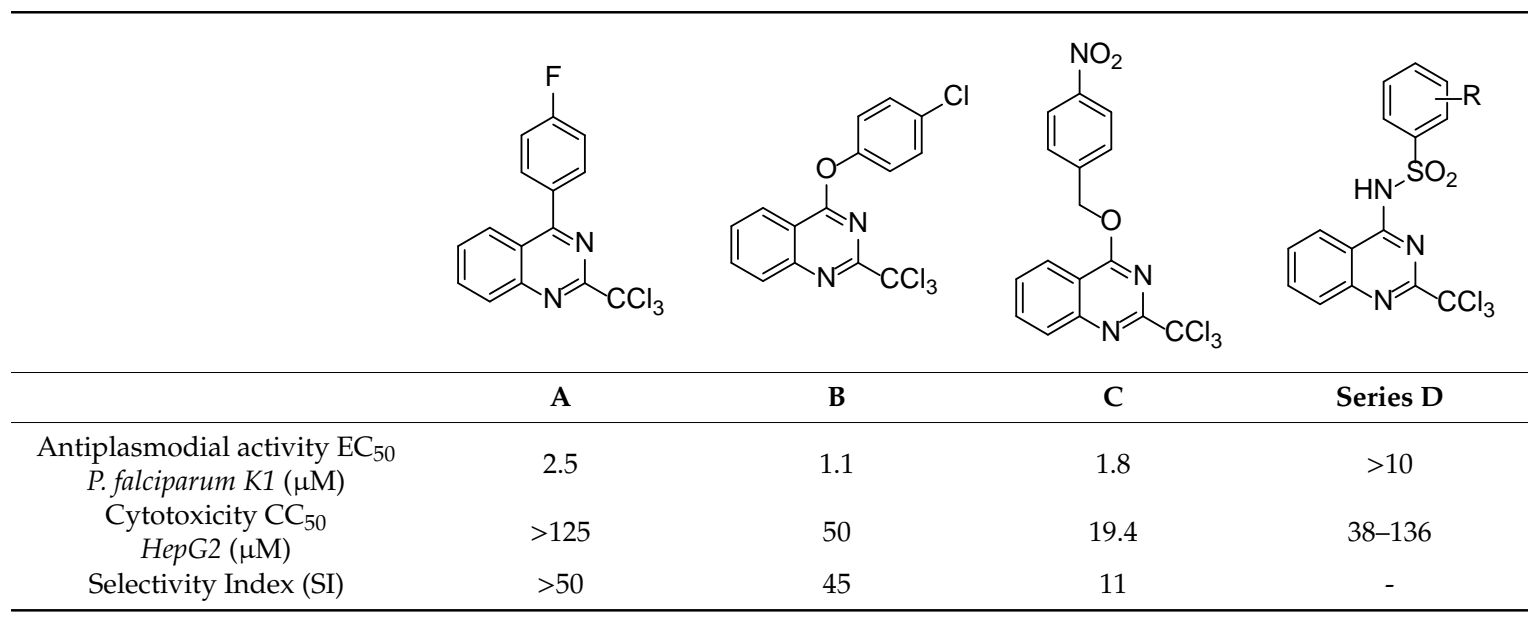

Reference molecules: Chloroquine $\left(\mathrm{EC}_{50}=0.8 \mu \mathrm{M}, \mathrm{CC}_{50}=30, \mathrm{SI}=37.5\right)$, Doxycycline $\left(\mathrm{EC}_{50}=6 \mu \mathrm{M}, \mathrm{CC}_{50}=20, \mathrm{SI}=\right.$ 3.3), Doxorubicin $\left(\mathrm{CC}_{50}=0.2 \mu \mathrm{M}\right)$. Selectivity index $=\mathrm{CC}_{50} / \mathrm{EC}_{50}$.

The aim of current study was to explore other 2-trichloromethylquinazolines bearing a two-atom linker in 4-carboxamido series, analogous to the 4-sulfonamide series D, and in 4-alkoxy series analogous to compounds $\mathbf{B}$ or $\mathbf{C}$ in aryloxy and benzyloxy series, respectively. The syntheses and in vitro biological evaluations are presented and discussed. 


\section{Results}

\subsection{Synthesis}

\subsubsection{Synthesis of 4-Carboxamido-2-Trichloromethylquinazoline Series}

We first sought to obtain the target compounds using key intermediate 4-amino-2trichloromethylquinazoline (1), previously described as generating the sulfonamide derivatives belonging to the $\mathbf{D}$ series [12]. Thus, using 4-chlorobenzoyl chloride in presence of sodium hydride in DMF, we obtained a mixture of starting material (1) and the formation of dibenzamide (3) resulting from a double substitution of the amino group (Table 2, Entry 1). Surprisingly, no formation of target compound (2) was observed. The same conditions were used at $0{ }^{\circ} \mathrm{C}$ and did not afford (2) (Entry 2). Increasing both base and acyl chloride only provided a mixture of (1) and dibenzamide (3) (Entries 3-4). Neither switching solvent types from DMF to THF (Entry 5), nor switching base types from NaH to $t$ BuOK (Entry 6) yielded (2). The use of organic bases such as NaHMDS or $\mathrm{NEt}_{3}$ was also unsuccessful, in particular with $\mathrm{NEt}_{3}$ with no conversion observed (Entries 7-9). Finally, in order to isolate the dibenzamide (3), the use of 5 equiv. of $\mathrm{NaH}$ led to total conversion and led to (3) with $90 \%$ yield (Entry 10).

Table 2. Studied parameters for the reaction of (1) with 4-chlorobenzoyl chloride.

\begin{tabular}{|c|c|c|c|c|c|c|}
\hline & $\mathrm{N}_{\mathrm{NCl}}^{\mathrm{NH}}$ & $\begin{array}{c}\text { Base } \\
\text { Solvent, Temp. }\end{array}$ & (2 & 3 & 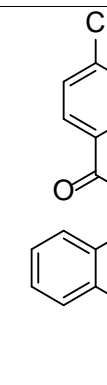 & \\
\hline $\mathbf{N}^{\circ}$ & $\begin{array}{c}\text { Base } \\
\text { (equiv.) }\end{array}$ & $\begin{array}{l}\text { Acyl Chloride } \\
\text { (equiv.) }\end{array}$ & Solvent & Temp. & Time & $\begin{array}{l}\text { LC-MS Estimated } \\
\text { Conversion }\end{array}$ \\
\hline 1 & $\begin{array}{c}\mathrm{NaH} \\
\text { (1.0 equiv) }\end{array}$ & 1.0 equiv & DMF & $0^{\circ} \mathrm{C} \rightarrow \mathrm{R} . \mathrm{T}$ & $12 \mathrm{~h}$ & (1) $80 \%$, , (3) $20 \%$ \\
\hline 2 & $\begin{array}{c}\mathrm{NaH} \\
\text { (1.0 equiv) }\end{array}$ & 1.0 equiv & DMF & $0^{\circ} \mathrm{C}$ & $24 \mathrm{~h}$ & (1) $95 \%,(3) 5 \%$ \\
\hline 3 & $\begin{array}{c}\mathrm{NaH} \\
\text { (1.5 equiv) }\end{array}$ & 1.5 equiv & DMF & $0^{\circ} \mathrm{C} \rightarrow \mathrm{R} . \mathrm{T}$ & $24 \mathrm{~h}$ & (1) $75 \%$, (3) $25 \%$ \\
\hline 4 & $\begin{array}{c}\mathrm{NaH} \\
\text { (2.0 Equiv) }\end{array}$ & 2.0 equiv & DMF & $0^{\circ} \mathrm{C} \rightarrow \mathrm{R} . \mathrm{T}$ & $12 \mathrm{~h}$ & (1) $60 \%$, (3) $40 \%$ \\
\hline 5 & $\begin{array}{c}\mathrm{NaH} \\
\text { (1.0 Equiv) }\end{array}$ & 1.0 equiv & THF & $0^{\circ} \mathrm{C} \rightarrow \mathrm{R} . \mathrm{T}$ & $12 \mathrm{~h}$ & (1) $90 \%$, , (3) $10 \%$ \\
\hline 6 & $\begin{array}{c}t \mathrm{BuOK} \\
\text { (1.1 equiv) }\end{array}$ & 1.5 equiv & DMF & $0^{\circ} \mathrm{C} \rightarrow \mathrm{R} . \mathrm{T}$ & $16 \mathrm{~h}$ & (1) $85 \%$, (3) $10 \%$ \\
\hline 7 & $\begin{array}{l}\text { NaHMDS } \\
\text { (1.1 equiv) }\end{array}$ & 1.0 equiv & THF & $0^{\circ} \mathrm{C} \rightarrow \mathrm{R} . \mathrm{T}$ & $16 \mathrm{~h}$ & $\begin{array}{l}\text { (1) } 50 \%,(2)<5 \% \text {, } \\
\text { (3) } 45 \%\end{array}$ \\
\hline 8 & $\begin{array}{c}\mathrm{Et}_{3} \mathrm{~N} \\
\text { (2.0 equiv) }\end{array}$ & 3.0 equiv & Dioxane & $105^{\circ} \mathrm{C}$ & $30 \mathrm{~min}$ & (1) $>95 \%$ \\
\hline 9 & $\begin{array}{c}\mathrm{Et}_{3} \mathrm{~N} \\
\text { (5.0 equiv) }\end{array}$ & 3.0 equiv & Dioxane & $105^{\circ} \mathrm{C}$ & $24 \mathrm{~h}$ & (1) > $>90 \%$ \\
\hline 10 & $\begin{array}{c}\mathrm{NaH} \\
\text { (5.0 Equiv) }\end{array}$ & 2.0 equiv & DMF & $0^{\circ} \mathrm{C} \rightarrow \mathrm{R} . \mathrm{T}$ & $24 \mathrm{~h}$ & (3) $90 \%$ * \\
\hline
\end{tabular}


In view of the ineffectiveness of this synthetic route, we changed tactics and started from 4-chloro-2-trichloromethylquinazoline (4), previously described [13] and used by our team in $\mathrm{S}_{\mathrm{N}}$ Ar reactions with various nucleophilic reagents [10,14,15] or Suzuki-Miyaura cross-coupling reactions [9]. Thus, commercial benzamide was deprotonated using $\mathrm{NaH}$ in DMF and reacted with chlorimine (4) in DMF, leading to the target compound (5) in 60\% yield (Scheme 1). As the conversion of the reaction was total and the yield was only impaired by the purification step, the reaction conditions were not modified and various commercially available substituted benzamides, heteroarylcarboxamides, and alkylcarboxamides were reacted (Table 3). The benzamides did not show a clear relationship between yields obtained (from 54 to 98\%) and their electron-donating/-withdrawing behavior, nor between yields and substituents position borne by their phenyl ring (3, 5-16). For pyridine-containing carboxamides (17-19), poor to good yields were obtained (22-81\%) related to purification issues in silica gel chromatography, even though the silica was deactivated by $\mathrm{NEt}_{3}$. With alkylcarboxamides, yields were generally lower than with benzamides (31-55\%) (20-25).

1) $\mathrm{NaH} 1.5$ equiv.

2)<smiles>Clc1nc(C(Cl)(Cl)Cl)nc2ccccc12</smiles><smiles>NC(=O)c1ccccc1</smiles>

1.5 equiv
(4) 1 equiv.

$0^{\circ} \mathrm{C}$ to rt DMF<smiles>O=C(Nc1nc(C(Cl)(Cl)Cl)nc2ccccc12)c1ccccc1</smiles>

$60 \%$
(5)

Scheme 1. Preparation of benzamide (5) from chlorimine (4).

Table 3. Structures, reaction yields, in vitro antiplasmodial and cytotoxicity evaluations of the 4-carboxamide-2-trichloro-methylquinazolines series (2-3, 5-25).

Molecule


Table 3. Cont

\begin{tabular}{|c|c|c|c|c|c|}
\hline Molecule & R- & Yield (\%) & HepG2 $\mathrm{CC}_{50}(\mu \mathrm{M})$ & $\mathrm{P} f \mathrm{~K} 1 \mathrm{EC}_{50}(\mu \mathrm{M})$ & $S^{d}$ \\
\hline 9 & & 88 & 29.4 & 1.34 & 21.9 \\
\hline 10 & & 80 & 19.9 & 2.86 & 6.9 \\
\hline 11 & & 98 & $>15.6^{c}$ & 5.23 & $>3.0$ \\
\hline 2 & & 74 & 21.0 & 0.99 & 21.2 \\
\hline 12 & & 82 & 16.4 & 1.54 & 10.6 \\
\hline 13 & & 83 & 27.3 & 9.04 & 4.1 \\
\hline 14 & & 62 & 19.5 & 1.30 & 15.0 \\
\hline 15 & & 95 & 31.4 & 3.50 & 9.0 \\
\hline 16 & & 75 & 27.7 & 0.94 & 29.5 \\
\hline 17 & & 81 & $>7.8^{\mathrm{c}}$ & 14.5 & $>0.5$ \\
\hline 18 & & 31 & 72.9 & 3.9 & 18.7 \\
\hline 19 & & 22 & 22.8 & 1.8 & 12.7 \\
\hline
\end{tabular}


Table 3. Cont.

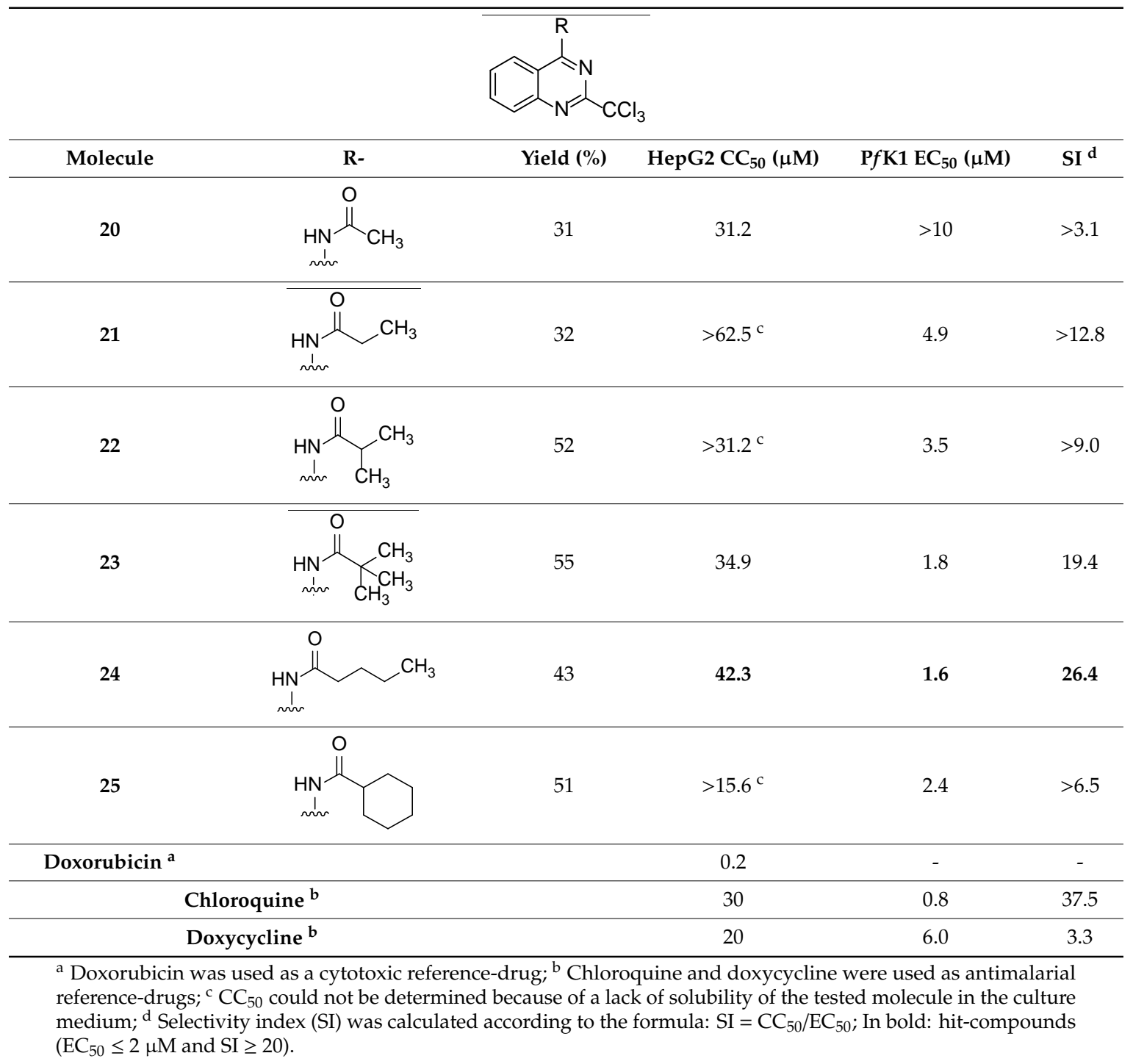

\subsubsection{Synthesis of 4-Alkoxy-2-Trichloromethylquinazoline Series}

As we previously showed that the introduction of an oxygen-containing substituents at position 4 of the quinazoline scaffold was favorable for the activity (compounds B and C, Table 1), we looked for oxygen-containing substituent in aliphatic series rather than previous aryl-containing derivatives. Using a previously reported reaction, a DMAP-catalyzed $S_{N} A r$ reaction between (4) and various aliphatic alcohols was conducted (Scheme 2). First, the reaction was conducted with linear aliphatic alcohol from $C_{1}$ to $C_{4}$ and afforded corresponding alkoxy derivatives (26-29) in good yields (75-81\%) (Table 4). Isopropoxy derivative (30) was obtained with the modest yield of 53\%. Propargyl alcohols led to target compounds (31-33) in very good yields (87-90\%). Reaction with ethylene glycol led to (34) with a modest yield (42\%) due to dimer formation, whereas 2-methoxyethanol afforded (35) in nearly quantitative yield. Halogen alkyl alcohols yielded corresponding products (36-40) in good yields (70-79\%) except for (38), which was obtained as an oil (28\%). Finally, various substituted aminoalcohols yielded target compounds (41-44) in modest $(44,20 \%)$ to good yields $(42,79 \%)$. 
<smiles>Clc1nc(C(Cl)(Cl)Cl)nc2ccccc12</smiles>

(4)

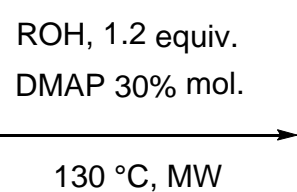

Toluene<smiles>[R]Oc1nc(C(Cl)(Cl)Cl)nc2ccccc12</smiles>

(25-43)

Scheme 2. Preparation of 4-alkoxy-2-trichloromethylquinazoline (25-43) from chlorimine (4).

Table 4. Structures, reaction yields, in vitro antiplasmodial and cytotoxicity evaluations of the 4-alkoxy-2-trichloromethylquinazolines (26-44).

\begin{tabular}{|c|c|c|c|c|c|}
\hline Molecule & R- & Yield (\%) & HepG2 $\mathrm{CC}_{50}(\mu \mathrm{M})$ & $\mathrm{P} f \mathrm{~K} 1 \mathrm{EC}_{50}(\mu \mathrm{M})$ & $\mathrm{SI}^{\mathrm{e}}$ \\
\hline 26 & & 81 & 39.3 & 7.1 & 5.5 \\
\hline 27 & & 79 & 47.1 & 4.7 & 10 \\
\hline 28 & & 75 & 54.8 & 3.5 & 15 \\
\hline 29 & & 79 & 82.4 & 5.8 & 14.2 \\
\hline 30 & & 53 & 101.5 & $>10^{\mathrm{d}}$ & $<10$ \\
\hline 31 & & 87 & 49.6 & 3.4 & 14.6 \\
\hline 32 & & 89 & 45.0 & $>10^{\mathrm{d}}$ & $<4.5$ \\
\hline 33 & & 90 & 30.6 & $>10^{\mathrm{d}}$ & $<3$ \\
\hline 34 & & 42 & 7.9 & 10.0 & 0.8 \\
\hline 35 & & 97 & 53.2 & 2.3 & 23.1 \\
\hline 36 & & 79 & $>62.5$ & 2.2 & $>28$ \\
\hline 37 & & 70 & 60.4 & 4.2 & 14.4 \\
\hline 38 & & 28 & 50.5 & 4.3 & 11.7 \\
\hline 39 & & 71 & 29.5 & 8.0 & 3.7 \\
\hline 40 & & 71 & $>62.5^{c}$ & 2.2 & $>28$ \\
\hline
\end{tabular}


Table 4. Cont.

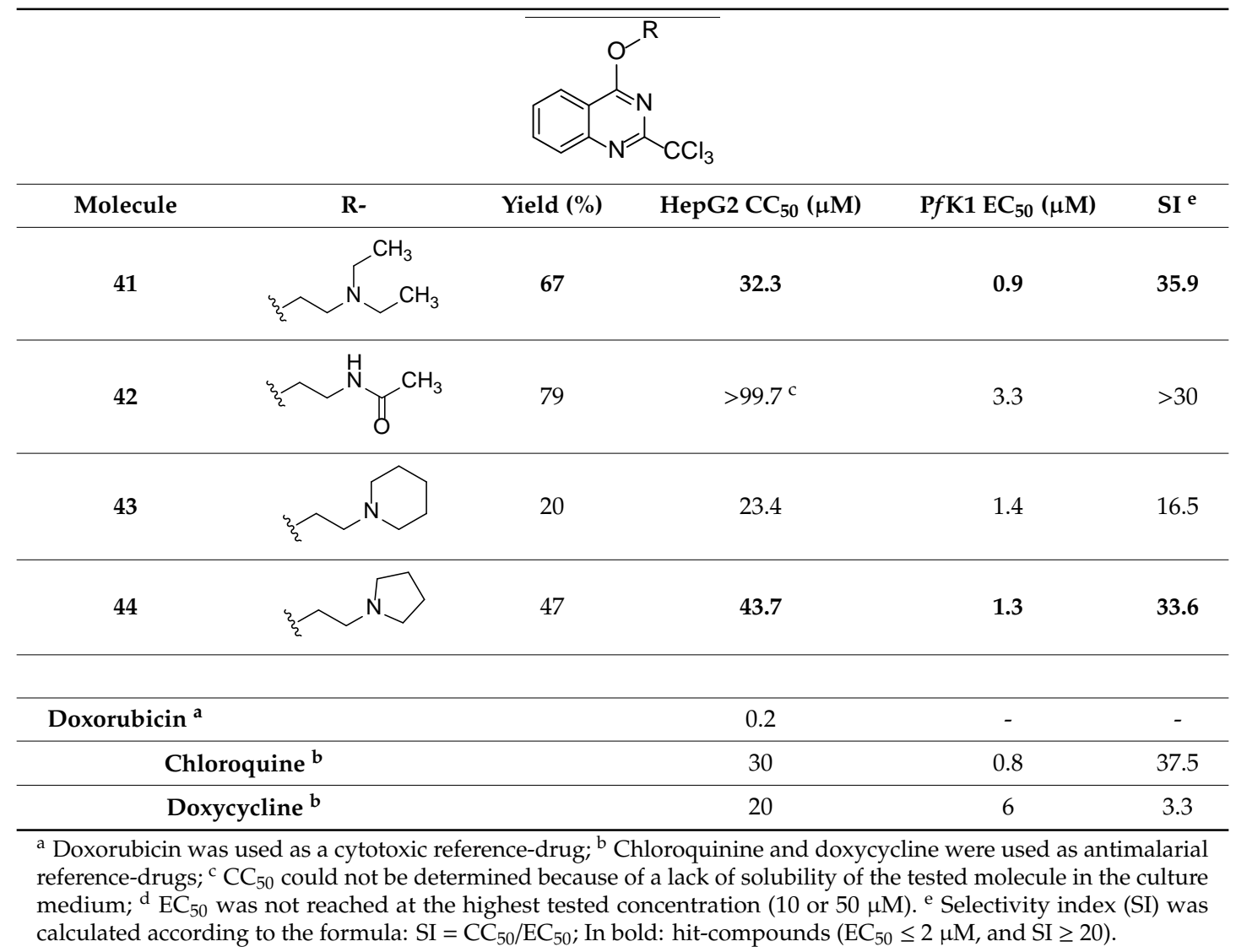

\subsection{Biological Evaluations}

All synthesized molecules were then evaluated in vitro against the multi-resistant K1 P. falciparum strain, by determining their $50 \%$ efficacy concentration $\left(\mathrm{EC}_{50}\right)$, and compared with two antimalarial drug-compounds: chloroquine and doxycycline. In parallel, these molecules were assessed in vitro on the HepG2 human hepatocyte cell line, by determining their $50 \%$ cytotoxic concentrations $\left(\mathrm{CC}_{50}\right)$ and comparing them to that of doxorubicin, used as a cytotoxic reference drug-compound, in order to calculate their respective selectivity indices $\left(\mathrm{SI}=\mathrm{CC}_{50} / \mathrm{EC}_{50}\right)$. The results are presented in Tables 3 and 4 .

\subsection{Structure-Activity Relationships (SAR)}

\subsubsection{SAR of 4-Carboxamido-2-Trichloromethylquinazoline Series}

For some synthesized compounds, lack of solubility hampered full determination of cytotoxicity $(8,11,17,20-21$, and 24) but not evaluation of antiplasmodial activity. It should be noted that in series D, there was no issue concerning solubility of sulfonamide derivatives [12]. For sufficiently soluble derivatives, cytotoxicity values ranged from 16.4 to $72.9 \mu \mathrm{M}$, high compared to that of doxorubicin $(0.2 \mu \mathrm{M})$. Interestingly, contrary to the sulfonamides in series $\mathbf{D}$, the carboxamide analogs exhibited an antiplasmodial activity $(0.94-14.5 \mu \mathrm{M})$, including dibenzamide (3) $(1.46 \mu \mathrm{M})$. Unsubstituted benzamide (5) displayed a moderate activity of $1.76 \mu \mathrm{M}$. The introduction of a strong electron-withdrawing group such as nitro group reduced the activity, and ortho (8) substitution was better than meta (7) and para (6). The influence of the substitution was inverted with a fluorine atom such as para (9) and displayed better activity $(1.34 \mu \mathrm{M})$ than meta (10) and para substitution (11). The same profile was observed with chloro-substituted benzamides leading to a micromolar antiplasmodial activity for para- $\mathrm{Cl}$ (2). Substituting para-Cl for para- $\mathrm{Br}(\mathbf{1 4})$ was not in favor of the activity $(1.30 \mu \mathrm{M}$ vs. $0.99 \mu \mathrm{M})$. Introducing 
para-CN (15) was also more detrimental to the activity $(3.5 \mu \mathrm{M})$, while para-OMe (16) showed the best activity against $\mathrm{K} 1 \mathrm{P}$. falciparum $(0.94 \mu \mathrm{M}, \mathrm{SI}=29.5)$. The pyridine-containing carboxamides (17-18) were less active (3.90-14.5 $\mu \mathrm{M})$, except for isonicotinamide (19), which had an $\mathrm{EC}_{50}$ of $1.8 \mu \mathrm{M}$. Regarding the alkylcarboxamides, acetamide (20) was not active $(>10 \mu \mathrm{M})$. The addition of carbon atoms to the alkyl chain led to more cluttered analogs that displayed similar activity to benzamides, like analogs (23) or (24) (1.8 and $1.6 \mu \mathrm{M})$. Cyclohexylcarboxamide (25) activity was slightly lower than that of terbutylcarboxamide (23). In conclusion, to provide the best antiplasmodial activity with good SI, para-substituted benzamides with chlorine, fluorine, methoxy, or non-cyclic alkylcarboxamide with fatty carbon chain were required.

\subsubsection{SAR of 4-Alkoxy-2-Trichloromethylquinazoline Series}

For the whole series, the solubility of the compounds was acceptable. Apart from alcohol (34) with a cytotoxicity value of $7.9 \mu \mathrm{M}$, the rest of the series was not cytotoxic (23.4-101.5 $\mu \mathrm{M})$, in comparison with doxorubicin. In this alkoxy series, amino-containing side chain were the most potent derivatives. We previously showed that 2-(trichloromethyl)quinazolin-4-ol $(R=H)$ was not active against $\mathrm{W} 2$ P. falciparum [10]. Interestingly, when $\mathrm{R}=\mathrm{Me}(\mathbf{2 6})$, a moderate activity was observed $\left(\mathrm{EC}_{50}=7.1 \mu \mathrm{M}\right)$, increasing with the number of carbons in the alkyl chain, up to 3 carbon atoms. The best activity $(3.5 \mu \mathrm{M})$ was obtained with a propoxy substituent (28), whereas with butoxy (29) the activity decreased again $(5.8 \mu \mathrm{M})$, the compound even becoming inactive with the bulkier isopropoxy group (30). Compound (31) resulting from the reaction of propargyl alcohol showed a modest activity, which was lost with substituted propargyl alcohols (32-33). Compound (34) bearing a 2-hydroxyethoxy group was almost inactive $(10 \mu \mathrm{M})$. Replacing the hydroxyl group of (34) by a methoxy group (35) or a chlorine atom (36) afforded more active derivatives $(2.3$ and $2.2 \mu \mathrm{M})$. The addition of one (37) or two atoms of carbon (38) in the chain of (36) decreased the activity two-fold (4.2 and $4.3 \mu \mathrm{M})$. The replacement of the chlorine atom of (36) by a fluorine atom (39) led to a decrease in activity $(8.0 \mu \mathrm{M})$ while a bromine atom (40) preserved it. Among aminoethoxy derivatives (41-44), diethylamino (41) was the most potent, with a submicromolar antiplasmodial activity $(0.9 \mu \mathrm{M})$ and a SI of 35.9. Cyclic analogs (43) and (44) were slightly less active than (41) whereas acetamide (42) was clearly less potent. In conclusion, we succeed in obtaining 4-O-substituted-quinazoline from inactive derivative 4-alcohol [10] to submicromolar active compounds in 4-alkoxyamino series.

To confirm the key role played by the 2-trichloromethylquinazoline moiety of the most potent compounds (16) and (41) in each studied series, derivatives without a $-\mathrm{CCl}_{3}$ group were synthesized for the two hit molecules: dehalogenated analogs $(45,47)$, 2-trifluromethyl analogs $(46,48)$ and unsubstituted analog (49) (Figures 2 and 3). All molecules were inactive against P. falciparum, illustrating the key role played by the $-\mathrm{CCl}_{3}$ group and consistent with our previous results. Thus, activity cliffs (ACs) [16] were observed when the $-\mathrm{CCl}_{3}$ group was replaced by similar group $\left(-\mathrm{CF}_{3}, \mathrm{CH}_{3}\right)$ or atom $(\mathrm{H})$ as a 50 -fold drop of antiplasmodial activity.

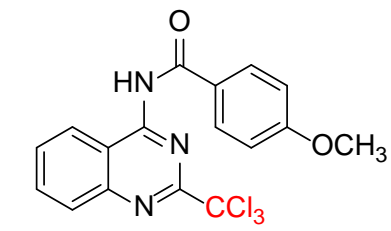

(16)

$$
\mathrm{IC}_{50} \text { P. falci. K1 }=0.94 \mu \mathrm{M}
$$

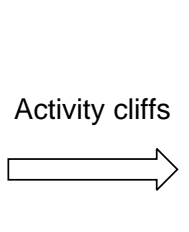

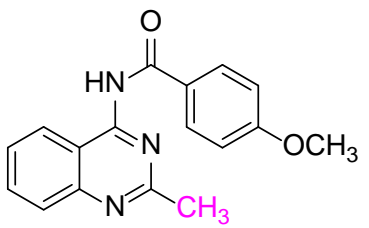

(45)<smiles>COc1ccc(C(=O)Nc2nc(C(F)(F)F)nc3ccccc23)cc1</smiles>

(46)

Figure 2. Comparison of the in vitro antiplasmodial activities of hit molecule (16) and negative controls (45-46). 
<smiles>CCN(CC)CCOc1nc(C(Cl)(Cl)Cl)nc2ccccc12</smiles>

(41)

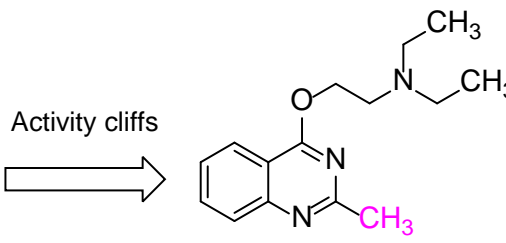

(47)

$\mathrm{IC}_{50} P$. falci. $K 1=0.9 \mu \mathrm{M}$<smiles>CCN(CC)CCOc1nc(C(F)(F)F)nc2ccccc12</smiles>

(48)<smiles>CCN(CC)CCOc1ncnc2ccccc12</smiles>

(49)

Figure 3. Comparison of the in vitro antiplasmodial activities of hit molecule (41) and negative controls (47-49).

The mechanism of action of the 2-trichloromethylquinazolines is not known, but it was clearly related to the presence of the $-\mathrm{CCl}_{3}$ group, which could act as a possibly alkylating group as methyl and trifluoromethyl analogues were inactive or the $-\mathrm{CCl}_{3}$ group could generate sigma-holes [17] with sulphur nucleophiles in cysteine proteases such as Falcipains as potential plasmodial targets [18].

\section{Material and Methods}

\subsection{General}

Melting points were determined on a Köfler melting point apparatus (Wagner \& Munz $\mathrm{GmbH}$, München, Germany) and are uncorrected. Elemental analyses were carried out at the Spectropole, Faculté des Sciences de Saint-Jêrome (Marseille) with a Thermo Finnigan EA1112 analyzer (Thermo Finnigan, San Jose, CA, USA). NMR spectra were recorded on a Bruker AV (Billerica, MA, USA) 200 or AV 250 spectrometers or a Bruker Avance NEO 400MHz NanoBay spectrometer at the Faculté de Pharmacie of Marseille or on a Bruker Avance III nanobay $400 \mathrm{MHz}$ spectrometer at the Spectropole, Faculté des Sciences de Saint-Jêrome (Marseille). ( ${ }^{1} \mathrm{H}$ NMR: reference $\mathrm{CHCl}_{3} \delta=7.26 \mathrm{ppm}$, reference DMSO- $d_{6} \delta=2.50 \mathrm{ppm}$ and ${ }^{13} \mathrm{C} \mathrm{NMR}$ : reference $\mathrm{CHCl}_{3} \delta=76.9$ ppm, reference DMSO- $d_{6}$ $\delta=39.52 \mathrm{ppm})$. The following adsorbent was used for column chromatography: silica gel 60 (Merck KGaA, Darmstadt, Germany, particle size 0.063-0.200 mm, 70-230 mesh ASTM). TLC was performed on $5 \mathrm{~cm} \times 10 \mathrm{~cm}$ aluminum plates coated with silica gel 60F-254 (Merck) in an appropriate eluent. Visualization was performed with ultraviolet light $(234 \mathrm{~nm})$. Purity of synthesized compounds was checked by LC/MS analyses, which were realized at the Faculté de Pharmacie of Marseille with a Thermo Scientific Accela High Speed LC System ${ }^{\circledR}$ (Waltham, MA, USA) coupled using a single quadrupole mass spectrometer Thermo MSQ Plus ${ }^{\circledR}$. The RP-HPLC column is a Thermo Hypersil Gold ${ }^{\circledR}$ $50 \times 2.1 \mathrm{~mm}\left(\mathrm{C}_{18}\right.$ bounded), with particles of a diameter of $1.9 \mathrm{~mm}$. The volume of sample injected on the column is $1 \mu \mathrm{L}$. Chromatographic analysis, total duration of $8 \mathrm{~min}$, is on the gradient of the following solvents: $\mathrm{t}=0 \mathrm{~min}$, methanol/water 50:50; $0<\mathrm{t}<4 \mathrm{~min}$, linear increase in the proportion of methanol to a methanol/water ratio of 95:5; $4<\mathrm{t}<6 \mathrm{~min}$, methanol/water 95:5; $6<\mathrm{t}<7 \mathrm{~min}$, linear decrease in the proportion of methanol to return to a methanol/water ratio of 50:50; $6<\mathrm{t}<7 \mathrm{~min}$, methanol/water 50:50. The water used was buffered with ammonium acetate $5 \mathrm{mM}$. The flow rate of the mobile phase was $0.3 \mathrm{~mL} / \mathrm{min}$. The retention times $\left(t_{R}\right)$ of the molecules analyzed are indicated in min. The microwave reactions were performed using multimode reactors: ETHOS Synth Lab station and MicroSYNTH ${ }^{\circledR}$ Lab terminal 1024 (Ethos start, MLS GmbH, Leutkirch, Germany.); or monomode reactors: Biotage Initiator $^{\circledR}$ classic in sealed vials with a power output of 0 to $400 \mathrm{~W}$. 4-Chloro-2-methylquinazoline, 4-chloro-2-trifluoromethylquinazoline, and 4-chloroquinazoline were purchased from Sigma-Aldrich (Saint Louis, MO, USA) or Fluorochem (Derbyshire, UK). The following Supplementary Materials are available online: 1H-NMR, 13C-NMR and HRMS data spectra of compounds 2, 9, 16, 24, 41, 44, 45, 46, 48 and 49. 


\subsection{4-Amino-2-Trichloromethylquinazoline (1)}

In a microwave vial equipped with a magnetic stir bar, 4-chloro-2-trichloromethylquinazoline [13] (700 mg, $2.48 \mathrm{mmol}, 1$ equiv.) and ammonia solution in THF (0.4 M, $18.6 \mathrm{~mL}, 7.45 \mathrm{mmol}, 3$ equiv.). The vial was capped and the suspension was then heated at $140{ }^{\circ} \mathrm{C}$ for $15 \mathrm{~min}$ ( $8 \mathrm{bar}$ ). The volatiles were removed under vacuum. The residue was poured into EtOAc $(100 \mathrm{~mL})$ and extracted twice with brine $(30 \mathrm{~mL})$. The organic layer was dried with $\mathrm{Na}_{2} \mathrm{SO}_{4}$, filtered and evaporated to afford (1) as white solid $(650 \mathrm{mg}, 100 \%)$. Mp $199{ }^{\circ} \mathrm{C} .{ }^{1} \mathrm{H}-\mathrm{NMR}$ (DMSO- $\left.d_{6}\right): \delta 8.33-8.27(\mathrm{~m}, 3 \mathrm{H}), 7.90-7.77(\mathrm{~m}$, 2H), 7.65-7.57 (m, 1H). ${ }^{13} \mathrm{C}-\mathrm{NMR}$ (DMSO- $\left.d_{6}\right): \delta 163.2,160.9,148.8,134.1,128.3,127.5,123.9,113.4,98.4$. LC-MS (ESI) Tr $2.37 \mathrm{~min}, \mathrm{~m} / z$ [M + H] $]^{+}$Calcd: 261.96, Found: 262.03. Anal. calcd. for $\mathrm{C}_{9} \mathrm{H}_{6} \mathrm{Cl}_{3} \mathrm{~N}_{3}: \mathrm{C}$, 41.18; H, 2.30; N, 16.01. Found: C, 41.43; H, 2.31; N, 16.29.

\subsection{4-Chloro-N-(4-Chlorobenzoyl)-N-(2-Trichloromethylquinazolin-4-yl)benzamide (3)}

To a solution of $60 \%$ sodium hydride in oil $(152 \mathrm{mg}, 3.81 \mathrm{mmol}, 5.0$ equiv.) in dry THF ( $4 \mathrm{~mL})$ at $0{ }^{\circ} \mathrm{C}$ was slowly added 4-amino-2-trichloromethylquinazoline ( $200 \mathrm{mg}, 0.76 \mathrm{mmol}, 1.0$ equiv). After $30 \mathrm{~min}$ of stirring at $\mathrm{rt}$, the reaction mixture was cooled again and the 4-chlorocarboxamide (1.52 mmol, 2.0 equiv.) was added portion wise. After this addition, the reaction was stirred at $\mathrm{rt}$ until the starting material disappeared. The excess of $\mathrm{NaH}$ was hydrolyzed with ice at $0{ }^{\circ} \mathrm{C}$. The mixture was extracted with EtOAc and washed three times with brine. The organic layer was dried with $\mathrm{Na}_{2} \mathrm{SO}_{4}$, filtered, and evaporated. The crude residue was triturated in dichloromethane, filtered, and recrystallized from appropriate solvent to give the desired compound.

Yield $90 \%$. White solid. Mp $218.2{ }^{\circ} \mathrm{C}$, (isopropanol). ${ }^{1} \mathrm{H}$ NMR $\left(400 \mathrm{MHz}\right.$, DMSO- $\left.d_{6}\right) \delta=8.33-8.23$ $(\mathrm{m}, 2 \mathrm{H}), 8.20(\mathrm{~d}, J=8.2 \mathrm{~Hz}, 1 \mathrm{H}), 8.03(\mathrm{ddd}, J=8.3,6.3,1.8 \mathrm{~Hz}, 1 \mathrm{H}), 7.95-7.90(\mathrm{~m}, 4 \mathrm{H}), 7.61-7.55$ $(\mathrm{m}, 4 \mathrm{H}) .{ }^{13} \mathrm{C}$ NMR $\left(101 \mathrm{MHz}, \mathrm{DMSO}-d_{6}\right) \delta=172.0(2 \mathrm{C}), 169.6,161.9,158.7,150.5,141.4,138.7,137.0$, $131.7,131.5,131.1(4 \mathrm{C}), 129.5,129.4(4 \mathrm{C}), 124.9,117.9$, 95.6. LC-MS (ESI+) $t_{R} 4.95 \mathrm{~min}, \mathrm{~m} / z$ [M $\left.+\mathrm{H}\right]^{+}$ 539.83/541.81/542.78/544.72/547.72. MW: $539.63 \mathrm{~g} \cdot \mathrm{mol}^{-1}$. HRMS $\mathrm{m} / \mathrm{z}[\mathrm{M}+\mathrm{H}]^{+}$calcd for $\mathrm{C}_{23} \mathrm{H}_{12} \mathrm{Cl}_{5} \mathrm{~N}_{3} \mathrm{O}_{2}$ : 539.9418, found: 539.9417 .

\subsection{4-Chloro-2-Trichloromethylquinazoline (4)}

4-Chloro-2-trichloromethylquinazoline (1) was prepared as described in the literature using a multimode microwave reactor at $800 \mathrm{~W}$ [13]. Yield $82 \%$. White solid. Mp $127^{\circ} \mathrm{C}$ (lit. $127^{\circ} \mathrm{C}$ ) [13]. ${ }^{1} \mathrm{H}$ NMR $\left(\mathrm{CDCl}_{3}, 200 \mathrm{MHz}\right) \delta=7.82-7.90(\mathrm{~m}, 1 \mathrm{H}), 8.03-8.12(\mathrm{~m}, 1 \mathrm{H}), 8.20-8.24(\mathrm{~m}, 1 \mathrm{H}), 8.33-8.38$ $(\mathrm{m}, 1 \mathrm{H})$.

\subsection{General Procedure for the Preparation of Compounds (2), (5-25)}

To a solution of the appropriate carboxamide compound (1.06 mmol, 1.5 equiv.) in dry DMF ( $3 \mathrm{~mL})$ at $0{ }^{\circ} \mathrm{C}$ under $\mathrm{N}_{2}, 60 \%$ sodium hydride in oil $(25.5 \mathrm{mg}, 1.06 \mathrm{mmol}, 1.5$ equiv) were added portion wise. The resulting mixture were added dropwise to a solution of 4-chloro-2-(trichloromethyl)quinazoline (4) $\left(200 \mathrm{mg}, 0.71 \mathrm{mmol}, 1.0\right.$ equiv.) in dry DMF $(2 \mathrm{~mL})$ at $0{ }^{\circ} \mathrm{C}$ under $\mathrm{N}_{2}$. The reaction was stirred overnight at rt. Then, the excess of $\mathrm{NaH}$ was hydrolyzed with ice. The reaction mixture was extracted with EtOAc and washed three times with brine. The organic layer was dried with $\mathrm{Na}_{2} \mathrm{SO}_{4}$, filtered, and evaporated. The crude product was purified by silica gel column chromatography and recrystallized from appropriate solvent to give the desired compound.

\subsubsection{4-Chloro-N-(2-Trichloromethylquinazolin-4-yl)benzamide (2)}

Yield 74\%. White solid. Mp $199^{\circ} \mathrm{C}$, (isopropanol). ${ }^{1} \mathrm{H}$ NMR $\left(400 \mathrm{MHz}, \mathrm{DMSO}-d_{6}\right) \delta=11.74(\mathrm{~s}, 1 \mathrm{H})$, $8.32(\mathrm{~d}, J=8.4 \mathrm{~Hz}, 1 \mathrm{H}), 8.18-8.10(\mathrm{~m}, 2 \mathrm{H}), 8.00(\mathrm{~d}, J=8.5 \mathrm{~Hz}, 2 \mathrm{H}), 7.90-7.80(\mathrm{~m}, 1 \mathrm{H}), 7.62(\mathrm{~d}, J=8.5 \mathrm{~Hz}$, 2H). ${ }^{13} \mathrm{C}$ NMR (101 MHz, DMSO- $\left.d_{6}\right) \delta=167.3,160.4,159.4,150.1,137.3,135.7,132.4,130.6$ (2C), 129.3, 128.6 (3C), 125.9, 117.2, 96.8. LC-MS (ESI+) $t_{R} 3.92 \mathrm{~min}, \mathrm{~m} / z$ [M + H] ${ }^{+} 399.03 / 401.59 / 403.98 / 405.94 \mathrm{MW}$ : 367.62 g. $\mathrm{mol}^{-1}$. HRMS $m / z[\mathrm{M}+\mathrm{H}]^{+}$calcd for $\mathrm{C}_{16} \mathrm{H}_{9} \mathrm{Cl}_{4} \mathrm{~N}_{3}$ : 401.9544, Found: 401.9545 . 


\subsubsection{N-(2-Trichloromethylquinazolin-4-yl)benzamide (5)}

Yield $60 \%$. White solid. Mp $183{ }^{\circ} \mathrm{C}$, (isopropanol). ${ }^{1} \mathrm{H}$ NMR $\left(400 \mathrm{MHz}\right.$, DMSO- $\left.d_{6}\right) \delta=11.67$ $(\mathrm{s}, 1 \mathrm{H}), 8.30(\mathrm{~d}, J=8.3 \mathrm{~Hz}, 1 \mathrm{H}), 8.15-8.09(\mathrm{~m}, 2 \mathrm{H}), 8.02-8.00(\mathrm{~m}, 2 \mathrm{H}), 7.86-7.82(\mathrm{~m}, 1 \mathrm{H}), 7.65(\mathrm{t}, J=7.4 \mathrm{~Hz}$, 1H), $7.55(\mathrm{t}, J=7.6 \mathrm{~Hz}, 2 \mathrm{H}) .{ }^{13} \mathrm{C}$ NMR $\left(101 \mathrm{MHz}, \mathrm{DMSO}-d_{6}\right) \delta=168.1,160.6,159.5,150.1,135.6,133.4$, $132.5,129.3,128.6(2 \mathrm{C}), 128.5,128.5(2 \mathrm{C}), 125.9,117.3,96.8$. LC-MS (ESI+) $t_{R} 3.38 \mathrm{~min}, \mathrm{~m} / z[\mathrm{M}+\mathrm{H}]^{+}$ 365.81/367.02/369.83. MW: 366.63 g. $\mathrm{mol}^{-1}$. HRMS $m / z[\mathrm{M}+\mathrm{H}]^{+}$calcd for $\mathrm{C}_{16} \mathrm{H}_{10} \mathrm{Cl}_{3} \mathrm{~N}_{3} \mathrm{O}: 365.9962$, Found: 365.9961 .

\subsubsection{4-Nitro-N-(2-Trichloromethylquinazolin-4-yl)benzamide (6)}

Yield 67\%. Yellow solid. Mp $214{ }^{\circ} \mathrm{C}$, (isopropanol). ${ }^{1} \mathrm{H}$ NMR $\left(400 \mathrm{MHz}, \mathrm{DMSO}-d_{6}\right) \delta=12.02$ (s, 1H), $8.42(\mathrm{~d}, J=8.3 \mathrm{~Hz}, 1 \mathrm{H}), 8.36-8.33(\mathrm{~m}, 2 \mathrm{H}), 8.14(\mathrm{dd}, J=6.3 \mathrm{~Hz}, 2.3 \mathrm{~Hz}, 4 \mathrm{H}), 7.92-7.85(\mathrm{~m}, 1 \mathrm{H})$. ${ }^{13} \mathrm{C}$ NMR $\left(101 \mathrm{MHz}\right.$, DMSO- $\left.d_{6}\right) \delta=167.4,159.8,159.2,150.0,149.4,139.7,135.8,129.9$ (2C), 129.4, 128.1, 125.7, 123.6 (2C), 116.7, 96.6. LC-MS (ESI+) $t_{R} 3.55 \mathrm{~min}, \mathrm{~m} / z[\mathrm{M}+\mathrm{H}]^{+}$410.98/413.01. MW: $411.63 \mathrm{~g} \cdot \mathrm{mol}^{-1}$. HRMS $m / z[\mathrm{M}+\mathrm{H}]^{+}$calcd for $\mathrm{C}_{16} \mathrm{H}_{9} \mathrm{Cl}_{3} \mathrm{~N}_{4} \mathrm{O}_{3}$ : 410.9813, Found: 410.9815.

\subsubsection{3-Nitro-N-(2-Trichloromethylquinazolin-4-yl)benzamide (7)}

Yield 60\%. White solid. Mp $196{ }^{\circ} \mathrm{C}$, (isopropanol). ${ }^{1} \mathrm{H}$ NMR $\left(400 \mathrm{MHz}, \mathrm{DMSO}-d_{6}\right) \delta=12.02$ $(\mathrm{s}, 1 \mathrm{H}), 8.79(\mathrm{~s}, 1 \mathrm{H}), 8.48(\mathrm{~d}, J=8.2 \mathrm{~Hz}, 1 \mathrm{H}), 8.43-8.36(\mathrm{~m}, 2 \mathrm{H}), 8.19-8.12(\mathrm{~m}, 2 \mathrm{H}), 7.93-7.79(\mathrm{~m}, 2 \mathrm{H})$. ${ }^{13} \mathrm{C}$ NMR $\left(101 \mathrm{MHz}\right.$, DMSO- $\left.d_{6}\right) \delta=166.4,160.0,159.3,150.1,147.7,135.8,135.2,134.9,130.3,129.4$, 128.6, 126.8, 126.0, 123.3, 117.0, 96.7. LC-MS (ESI+) $t_{R} 3.50 \mathrm{~min}, \mathrm{~m} / z[\mathrm{M}+\mathrm{H}]^{+} 410.98 / 412.97 / 410.98$. MW: 411.63 g.mol ${ }^{-1}$. HRMS m/z [M+Na] $]^{+}$calcd for $\mathrm{C}_{16} \mathrm{H}_{9} \mathrm{Cl}_{3} \mathrm{~N}_{4} \mathrm{O}_{3}: 432.9632$, Found: 432.9627.

\subsubsection{2-Nitro-N-(2-Trichloromethylquinazolin-4-yl)benzamide (8)}

Yield 54\%. White solid. Mp $257^{\circ} \mathrm{C}$, (isopropanol). ${ }^{1} \mathrm{H}$ NMR $\left(400 \mathrm{MHz}, \mathrm{DMSO}-d_{6}\right) \delta=12.19$ $(\mathrm{s}, 1 \mathrm{H}), 8.71(\mathrm{~d}, J=8.1 \mathrm{~Hz}, 1 \mathrm{H}), 8.33(\mathrm{dd}, J=8.3,0.8 \mathrm{~Hz}, 1 \mathrm{H}), 8.17-8.07(\mathrm{~m}, 1 \mathrm{H}), 8.04(\mathrm{~d}, J=7.6 \mathrm{~Hz}$, $1 \mathrm{H}), 7.90(\mathrm{ddd}, J=8.2 \mathrm{~Hz}, 7.0 \mathrm{~Hz}, 1.2 \mathrm{~Hz}, 1 \mathrm{H}), 7.79(\mathrm{td}, J=7.5 \mathrm{~Hz}, 1.1 \mathrm{~Hz}, 1 \mathrm{H}), 7.73-7.66(\mathrm{~m}, 1 \mathrm{H})$, $7.63(\mathrm{dd}, J=7.5 \mathrm{~Hz}, 1.2 \mathrm{~Hz}, 1 \mathrm{H}) .{ }^{13} \mathrm{C}$ NMR $\left(101 \mathrm{MHz}, \mathrm{DMSO}-d_{6}\right) \delta=168.0,158.7,157.4,149.3,144.9$, 135.6, 135.1, 134.1, 130.1, 129.5, 128.7, 127.1, 124.9, 124.4, 114.5, 96.2. LC-MS (ESI+) $t_{R} 3.23 \mathrm{~min}$, $m / z[\mathrm{M}+\mathrm{H}]^{+}$410.99/412.90/414.88. MW: $411.63 \mathrm{~g} \cdot \mathrm{mol}^{-1}$. HRMS $\mathrm{m} / z[\mathrm{M}+\mathrm{H}]^{+}$calcd for $\mathrm{C}_{16} \mathrm{H}_{9} \mathrm{Cl}_{3} \mathrm{~N}_{4} \mathrm{O}_{3}$ : 410.9813, Found: 410.9804.

\subsubsection{4-Fluoro-N-(2-Trichloromethylquinazolin-4-yl)benzamide (9)}

Yield 88\%. White solid. Mp $166{ }^{\circ} \mathrm{C}$, (isopropanol). ${ }^{1} \mathrm{H}$ NMR $\left(400 \mathrm{MHz}, \mathrm{DMSO}-d_{6}\right) \delta=11.69(\mathrm{~s}, 1 \mathrm{H})$, $8.30(\mathrm{~d}, J=8.4 \mathrm{~Hz}, 1 \mathrm{H}), 8.17-8.11(\mathrm{~m}, 2 \mathrm{H}), 8.11-8.06(\mathrm{~m}, 2 \mathrm{H}), 7.89-7.81(\mathrm{~m}, 1 \mathrm{H}), 7.39(\mathrm{t}, J=8.8 \mathrm{~Hz}$, 2H). ${ }^{13} \mathrm{C}$ NMR (101 MHz, DMSO- $\left.d_{6}\right) \delta 167.0,164.6(\mathrm{~d}, J=250.5 \mathrm{~Hz}), 160.5,159.4,150.0,135.6,131.5$ $(\mathrm{d}, J=9.3 \mathrm{~Hz}), 129.9(\mathrm{~d}, J=2.8 \mathrm{~Hz}), 129.2,128.5,125.9,117.2,115.5(\mathrm{~d}, J=22.0 \mathrm{~Hz}), 96.8$. LC-MS (ESI+) $t_{R} 3.58 \mathrm{~min}, \mathrm{~m} / z[\mathrm{M}+\mathrm{H}]^{+}$384.05/386.02/387.95. MW: $384.62 \mathrm{~g} \cdot \mathrm{mol}^{-1}$. HRMS $m / z[\mathrm{M}+\mathrm{H}]^{+}$calcd for $\mathrm{C}_{16} \mathrm{H}_{9} \mathrm{Cl}_{3} \mathrm{FN}_{3} \mathrm{O}: 405.9687$, Found: 405.9688 .

\subsubsection{3-Fluoro-N-(2-Trichloromethylquinazolin-4-yl)benzamide (10)}

Yield 80\%. Yellow solid. Mp $152{ }^{\circ} \mathrm{C}$, (isopropanol). ${ }^{1} \mathrm{H}$ NMR $\left(400 \mathrm{MHz}, \mathrm{DMSO}-d_{6}\right) \delta=11.74$ $(\mathrm{s}, 1 \mathrm{H}), 8.32(\mathrm{~d}, J=6.5 \mathrm{~Hz}, 1 \mathrm{H}), 8.17-8.09(\mathrm{~m}, 2 \mathrm{H}), 7.89-7.78(\mathrm{~m}, 3 \mathrm{H}), 7.63-7.57(\mathrm{~m}, 1 \mathrm{H}), 7.50(\mathrm{dt}, J=8.6$, $2.1 \mathrm{~Hz}, 1 \mathrm{H}) .{ }^{13} \mathrm{C}$ NMR $\left(101 \mathrm{MHz}, \mathrm{DMSO}-d_{6}\right) \delta=166.9(\mathrm{~d}, J=2.6 \mathrm{~Hz}), 161.9(\mathrm{~d}, J=244.5 \mathrm{~Hz}), 160.2$, $159.4,150.1,135.8(\mathrm{~d}, J=7.2 \mathrm{~Hz}), 135.7,130.6(\mathrm{~d}, J=8.0 \mathrm{~Hz}), 129.3,128.6,125.9,124.7(\mathrm{~d}, J=2.7 \mathrm{~Hz})$, $119.3(\mathrm{~d}, J=21.2 \mathrm{~Hz}), 117.2,115.4(\mathrm{~d}, J=23.2 \mathrm{~Hz}), 96.7$. LC-MS (ESI+) $t_{R} 3.57 \mathrm{~min}, \mathrm{~m} / z[\mathrm{M}+\mathrm{H}]^{+}$ 383.99/385.06/386.08/388.05/389.05. MW: $384.62 \mathrm{~g} \cdot \mathrm{mol}^{-1}$. HRMS m/z [M+Na] $]^{+}$calcd for $\mathrm{C}_{16} \mathrm{H}_{9} \mathrm{Cl}_{3} \mathrm{FN}_{3} \mathrm{O}$ : 405.9687, Found: 405.9688. 


\subsubsection{2-Fluoro-N-(2-Trichloromethylquinazolin-4-yl)benzamide (11)}

Yield 98\%. White solid. Mp $190{ }^{\circ} \mathrm{C}$, (isopropanol). ${ }^{1} \mathrm{H}$ NMR $\left(400 \mathrm{MHz}\right.$, DMSO- $\left.d_{6}\right) \delta=11.95$ $(\mathrm{s}, 1 \mathrm{H}), 8.53(\mathrm{~d}, J=8.4 \mathrm{~Hz}, 1 \mathrm{H}), 8.11(\mathrm{q}, J=8.5 \mathrm{~Hz}, 2 \mathrm{H}), 7.93-7.86(\mathrm{~m}, 1 \mathrm{H}), 7.71(\mathrm{td}, J=7.5,1.2 \mathrm{~Hz}, 1 \mathrm{H})$, $7.57-7.50(\mathrm{~m}, 1 \mathrm{H}), 7.30(\mathrm{t}, J=7.5 \mathrm{~Hz}, 1 \mathrm{H}), 7.21(\mathrm{dd}, J=10.3,8.8 \mathrm{~Hz}, 1 \mathrm{H}) .{ }^{13} \mathrm{C}$ NMR $\left(101 \mathrm{MHz}\right.$, DMSO- $\left.d_{6}\right)$ $\delta=166.1,159.1,159.0,158.8(\mathrm{~d}, J=249.4 \mathrm{~Hz}), 149.8,135.6,133.0(\mathrm{~d}, J=8.7 \mathrm{~Hz}), 130.2(\mathrm{~d}, J=2.5 \mathrm{~Hz})$, 129.5, 128.6, 124.8, $124.7(\mathrm{~d}, J=3.4 \mathrm{~Hz}), 124.1(\mathrm{~d}, J=13.9 \mathrm{~Hz}), 116.1(\mathrm{~d}, J=21.7 \mathrm{~Hz}), 115.6,96.5$. LC-MS (ESI+) $t_{R} 3.44 \mathrm{~min}, \mathrm{~m} / z[\mathrm{M}+\mathrm{H}]^{+} 384.01 / 386.00 / 388.00$. MW: $384.62 \mathrm{~g} \cdot \mathrm{mol}^{-1}$. HRMS $m / z[\mathrm{M}+\mathrm{H}]^{+} \mathrm{calcd}^{-}$ for $\mathrm{C}_{16} \mathrm{H}_{9} \mathrm{Cl}_{3} \mathrm{FN}_{3} \mathrm{O}: 383.9868$, Found: 382.9795 .

\subsubsection{3-Chloro-N-(2-Trichloromethylquinazolin-4-yl)benzamide (12)}

Yield $82 \%$. White solid. Mp $139{ }^{\circ} \mathrm{C}$, (isopropanol). ${ }^{1} \mathrm{H}$ NMR $\left(400 \mathrm{MHz}, \mathrm{DMSO}-d_{6}\right) \delta=11.81$ $(\mathrm{s}, 1 \mathrm{H}), 8.35(\mathrm{~d}, J=8.4 \mathrm{~Hz}, 1 \mathrm{H}), 8.19-8.10(\mathrm{~m}, 2 \mathrm{H}), 8.06(\mathrm{~s}, 1 \mathrm{H}), 7.94(\mathrm{~d}, J=8.3 \mathrm{~Hz}, 1 \mathrm{H}), 7.90-7.82(\mathrm{~m}, 1 \mathrm{H})$, $7.71(\mathrm{~d}, J=8.2 \mathrm{~Hz}, 1 \mathrm{H}), 7.58(\mathrm{t}, J=7.9 \mathrm{~Hz}, 1 \mathrm{H}) .{ }^{13} \mathrm{C} \mathrm{NMR}\left(101 \mathrm{MHz}, \mathrm{DMSO}-d_{6}\right) \delta=166.8,160.2,159.4$, $150.1,135.7,135.6,133.2,132.2,130.4,129.3,128.6,128.3,127.3,126.0,117.1,96.8$. LC-MS (ESI+) $t_{R}$ $3.98 \mathrm{~min}, \mathrm{~m} / z[\mathrm{M}+\mathrm{H}]^{+}$401.92/403.97/405.89. MW: $401.07 \mathrm{~g} \cdot \mathrm{mol}^{-1}$. HRMS $\mathrm{m} / z[\mathrm{M}+\mathrm{H}]^{+}$calcd for $\mathrm{C}_{16} \mathrm{H}_{9} \mathrm{Cl}_{4} \mathrm{~N}_{3} \mathrm{O}: 401.9544$, Found: 401.9546.

\subsubsection{2-Chloro-N-(2-Trichloromethylquinazolin-4-yl)benzamide (13)}

Yield 83\%. Yellow solid. Mp $171{ }^{\circ} \mathrm{C}$, (isopropanol). ${ }^{1} \mathrm{H}$ NMR $\left(400 \mathrm{MHz}, \mathrm{DMSO}-d_{6}\right) \delta=12.02$ $(\mathrm{s}, 1 \mathrm{H}), 8.59(\mathrm{~d}, J=8.4 \mathrm{~Hz}, 1 \mathrm{H}), 8.11(\mathrm{dd}, J=14.1,7.3 \mathrm{~Hz}, 2 \mathrm{H}), 7.93-7.86(\mathrm{~m}, 1 \mathrm{H}), 7.58(\mathrm{dd}, J=7.3,1.6 \mathrm{~Hz}$, 1H), 7.51-7.34 (m, 3H). ${ }^{13} \mathrm{C}$ NMR (101 MHz, DMSO-d $\left.d_{6}\right)$ 168.2, 159.1, 158.4, 149.7, 136.1, 135.6, 131.2, $129.79,129.78,129.5,129.1,128.6,127.4,124.7,115.3,96.4$. LC-MS (ESI+) $t_{R} 3.66 \mathrm{~min}, \mathrm{~m} / z$ [M + H] ${ }^{+}$ 398.83/401.88/403.98. MW: 401.07 g. $\mathrm{mol}^{-1}$. HRMS m/z [M + H] ${ }^{+}$calcd for $\mathrm{C}_{16} \mathrm{H}_{9} \mathrm{Cl}_{4} \mathrm{~N}_{3} \mathrm{O}: 401.9544$, Found: 401.9543 .

\subsubsection{4-Bromo-N-(2-Trichloromethylquinazolin-4-yl)benzamide (14)}

Yield 62\%. Beige solid. Mp $201{ }^{\circ} \mathrm{C}$, (isopropanol). ${ }^{1} \mathrm{H}$ NMR $\left(400 \mathrm{MHz}\right.$, DMSO- $\left.d_{6}\right) \delta=11.73(\mathrm{~s}, 1 \mathrm{H})$, $8.29(\mathrm{dd}, J=18.3 \mathrm{~Hz}, 8.5 \mathrm{~Hz}, 1 \mathrm{H}), 8.18-8.09(\mathrm{~m}, 2 \mathrm{H}), 7.92(\mathrm{~d}, J=8.5 \mathrm{~Hz}, 2 \mathrm{H}), 7.85(\mathrm{ddd}, J=8.3 \mathrm{~Hz}$, $5.6 \mathrm{~Hz}, 2.6 \mathrm{~Hz}, 1 \mathrm{H}), 7.76(\mathrm{~d}, J=8.5 \mathrm{~Hz}, 2 \mathrm{H}) .{ }^{13} \mathrm{C}$ NMR $\left(101 \mathrm{MHz}, \mathrm{DMSO}-d_{6}\right) \delta=167.4,160.3,159.3$, 150.0, 135.6, 132.7, 131.5 (2 C), 130.6 (2 C), 129.3, 128.5, 126.2, 125.8, 117.1, 96.8. LC-MS (ESI+) $t_{R}$ $4.20 \mathrm{~min}, \mathrm{~m} / z[\mathrm{M}+\mathrm{H}]^{+}$443.79/445.83/447.73/449.59. MW: $445.53 \mathrm{~g} \cdot \mathrm{mol}^{-1}$. HRMS m/z [M + H] $]^{+}$calcd for $\mathrm{C}_{16} \mathrm{H}_{9} \mathrm{BrCl}_{3} \mathrm{~N}_{3} \mathrm{O}: 445.9043$, Found: 445.9046 .

\subsubsection{4-Cyano-N-(2-Trichloromethylquinazolin-4-yl)benzamide (15)}

Yield 95\%. White solid. Mp $170{ }^{\circ} \mathrm{C}$, (isopropanol). ${ }^{1} \mathrm{H}$ NMR $\left(400 \mathrm{MHz}, \mathrm{DMSO}-d_{6}\right) \delta=11.93$ $(\mathrm{s}, 1 \mathrm{H}), 8.39(\mathrm{~d}, J=8.4 \mathrm{~Hz}, 1 \mathrm{H}), 8.14(\mathrm{~d}, J=3.8 \mathrm{~Hz}, 2 \mathrm{H}), 8.07(\mathrm{~d}, J=8.3 \mathrm{~Hz}, 2 \mathrm{H}), 8.01(\mathrm{~d}, J=8.3 \mathrm{~Hz}$, $2 \mathrm{H}), 7.87(\mathrm{dt}, J=8.3,4.0 \mathrm{~Hz}, 1 \mathrm{H}) .{ }^{13} \mathrm{C}$ NMR $\left(101 \mathrm{MHz}, \mathrm{DMSO}-d_{6}\right) \delta=167.6,159.9,159.2,150.0,138.0$, $135.8,132.5$ (2 C), 129.4, 129.2 (2 C), 128.6, 125.7, 118.2, 116.8, 114.3, 96.7. LC-MS (ESI+) $t_{R} 3.03 \mathrm{~min}$, $m / z[\mathrm{M}+\mathrm{H}]^{+}$390.98/393.05/394.94. MW: 391.64 g.mol ${ }^{-1}$. HRMS m/z [M + H] $]^{+}$calcd for $\mathrm{C}_{17} \mathrm{H}_{9} \mathrm{Cl}_{3} \mathrm{~N}_{4} \mathrm{O}$ : 390.9915, Found: 390.9911.

\subsubsection{4-Methoxy-N-(2-Trichloromethylquinazolin-4-yl)benzamide (16)}

Yield 75\%. Yellow solid. Mp $192{ }^{\circ} \mathrm{C}$, (isopropanol). ${ }^{1} \mathrm{H}$ NMR $\left(400 \mathrm{MHz}, \mathrm{DMSO}-d_{6}\right) \delta=11.52$ (s, $1 \mathrm{H}), 7.40(\mathrm{~d}, J=8.4 \mathrm{~Hz}, 1 \mathrm{H}), 7.33-7.25(\mathrm{~m}, 2 \mathrm{H}), 7.20(\mathrm{~d}, J=8.8 \mathrm{~Hz}, 2 \mathrm{H}), 7.04-6.94(\mathrm{~m}, 1 \mathrm{H}), 6.26$ $(\mathrm{d}, J=8.8 \mathrm{~Hz}, 2 \mathrm{H}), 3.03(\mathrm{~s}, 3 \mathrm{H}) .{ }^{13} \mathrm{C}$ NMR $\left(101 \mathrm{MHz}, \mathrm{DMSO}-d_{6}\right) \delta=167.1,162.8,160.9,159.5,150.0$, 135.5, 130.9 (2C), 129.1, 128.5, 126.1, 125.3, 117.45, 113.7 (2 C), 97.0, 55.5. LC-MS (ESI+) $t_{R} 3.46 \mathrm{~min}$, $\mathrm{m} / \mathrm{z}[\mathrm{M}+\mathrm{H}]^{+}$396.08/398.87/400.53. MW: $396.66 \mathrm{~g} \cdot \mathrm{mol}^{-1}$. HRMS $\mathrm{m} / z[\mathrm{M}+\mathrm{H}]^{+}$calcd for $\mathrm{C}_{17} \mathrm{H}_{12} \mathrm{Cl}_{3} \mathrm{~N}_{3} \mathrm{O}_{2}$ : 396.0068, Found: 396.0062. 


\subsubsection{N-(2-Trichloromethylquinazolin-4-yl)picolinamide (17)}

Yield $81 \%$. Beige solid. Mp $214{ }^{\circ} \mathrm{C}$, (isopropanol). ${ }^{1} \mathrm{H}$ NMR $\left(400 \mathrm{MHz}, \mathrm{DMSO}-d_{6}\right) \delta=11.72(\mathrm{~s}, 1 \mathrm{H})$, $8.76(\mathrm{~d}, J=4.5 \mathrm{~Hz}, 1 \mathrm{H}), 8.37(\mathrm{~d}, J=8.3 \mathrm{~Hz}, 1 \mathrm{H}), 8.22-8.10(\mathrm{~m}, 4 \mathrm{H}), 7.95-7.88(\mathrm{~m}, 1 \mathrm{H}), 7.78-7.69(\mathrm{~m}, 1 \mathrm{H})$. ${ }^{13} \mathrm{C}$ NMR $\left(101 \mathrm{MHz}\right.$, DMSO- $\left.d_{6}\right) \delta=164.0,159.5,159.1,150.0,149.1,148.7,138.4,135.8,129.5,128.6$, 127.6, 125.1, 123.1, 116.9, 96.9. LC-MS (ESI+) $t_{R} 3.4 \mathrm{~min}, \mathrm{~m} / z[\mathrm{M}+\mathrm{H}]^{+} 365.74 / 367.13 / 368.70 / 371.04$. MW: 367.62 g. $\mathrm{mol}^{-1}$. HRMS $\mathrm{m} / z$ [M + H] $]^{+}$calcd for $\mathrm{C}_{15} \mathrm{H}_{9} \mathrm{Cl}_{3} \mathrm{~N}_{4} \mathrm{O}: 366.9915$, Found: 366.9912.

\subsubsection{N-(2-Trichloromethylquinazolin-4-yl)nicotinamide (18)}

Yield 20\%. White solid. Mp $208{ }^{\circ} \mathrm{C}$, (isopropanol). ${ }^{1} \mathrm{H}$ NMR $\left(400 \mathrm{MHz}\right.$, DMSO- $\left.d_{6}\right) \delta=11.91$ $(\mathrm{m}, 1 \mathrm{H}), 9.10(\mathrm{ls}, 1 \mathrm{H}), 8.79(\mathrm{ls}, 1 \mathrm{H}), 8.39(\mathrm{~d}, J=8.4 \mathrm{~Hz}, 1 \mathrm{H}), 8.30(\mathrm{~d}, J=7.9 \mathrm{~Hz}, 1 \mathrm{H}), 8.14(\mathrm{~d}, J=3.7 \mathrm{~Hz}$, 2H), 7.92-7.82 (m, 1H), $7.58(\mathrm{dd}, J=7.8,4.8 \mathrm{~Hz}, 1 \mathrm{H}) .{ }^{13} \mathrm{C}$ NMR $\left(101 \mathrm{MHz}\right.$, DMSO- $\left.d_{6}\right) \delta=167.2,160.1$, $159.3,152.7,150.1,149.4,136.3,135.8,129.7,129.4,128.6,125.9,123.6,116.9,96.7$. LC-MS (ESI+) $t_{R}$ $2.44 \mathrm{~min}, \mathrm{~m} / \mathrm{z}[\mathrm{M}+\mathrm{H}]^{+}$365.65/368.50/371.07. MW: $367.62 \mathrm{~g} \cdot \mathrm{mol}^{-1}$. HRMS $m / z[\mathrm{M}+\mathrm{H}]^{+}$calcd for $\mathrm{C}_{15} \mathrm{H}_{9} \mathrm{Cl}_{3} \mathrm{~N}_{4} \mathrm{O}: 366.9915$, Found: 366.9911.

\subsubsection{N-(2-Trichloromethylquinazolin-4-yl)isonicotinamide (19)}

Yield 22\%. White solid. Mp $151{ }^{\circ} \mathrm{C}$, (isopropanol). ${ }^{1} \mathrm{H}$ NMR $\left(400 \mathrm{MHz}, \mathrm{DMSO}-d_{6}\right) \delta=12.04$ (s, 1H), $8.77(\mathrm{~d}, J=5.6 \mathrm{~Hz}, 1 \mathrm{H}), 8.44(\mathrm{~d}, J=8.3 \mathrm{~Hz}, 1 \mathrm{H}), 8.15(\mathrm{~d}, J=3.6 \mathrm{~Hz}, 2 \mathrm{H}), 7.94-7.85(\mathrm{~m}, 2 \mathrm{H}), 7.82$ $(\mathrm{d}, J=4.9 \mathrm{~Hz}, 2 \mathrm{H}) .{ }^{13} \mathrm{C}$ NMR $\left(101 \mathrm{MHz}, \mathrm{DMSO}-d_{6}\right) \delta=167.7,159.7,159.2,150.3,150.0(2 \mathrm{C}), 141.3,135.9$, 129.5, 128.6, 125.7, 122.0 (2C), 116.7, 96.7. LC-MS (ESI+) $t_{R} 2.38 \mathrm{~min}, \mathrm{~m} / z[\mathrm{M}+\mathrm{H}]^{+} 365.72 / 368.60 / 371.04$. MW: 367.62 g.mol ${ }^{-1}$. HRMS $\mathrm{m} / z$ [M + H] $]^{+}$calcd for $\mathrm{C}_{15} \mathrm{H}_{9} \mathrm{Cl}_{3} \mathrm{~N}_{4} \mathrm{O}: 366.9915$, Found: 366.9911.

\subsubsection{N-(2-Trichloromethylquinazolin-4-yl)acetamide (20)}

Yield $31 \%$. White solid. $\mathrm{Mp} 217^{\circ} \mathrm{C}$, (isopropanol). ${ }^{1} \mathrm{H}$ NMR $\left(250 \mathrm{MHz}, \mathrm{CDCl}_{3}\right) \delta=8.54$ (br s, 1H), 8.15-8.19 (m, 1H), 7.96-8.03 (m, 2H), 7.73-7.80 (m, 1H), $2.85(\mathrm{~s}, 3 \mathrm{H}) .{ }^{13} \mathrm{C} \mathrm{NMR}\left(63 \mathrm{MHz}, \mathrm{CDCl}_{3}\right)$ $\delta=173.8,159.9,157.0,150.4,134.8,130.0,129.4,122.0,114.3,97.0,26.7$. LC-MS (ESI+) $t_{R} 3.36 \mathrm{~min}$, $m / z[\mathrm{M}+\mathrm{H}]^{+}$303.98/305.91/307.99. MW: 304.56 g.mol ${ }^{-1}$. Anal. Calcd for $\mathrm{C}_{11} \mathrm{H}_{8} \mathrm{Cl}_{3} \mathrm{~N}_{3} \mathrm{O}: \mathrm{C}, 43.38$; H, 2.65; N, 13.80. Found: C, 42.84; H, 2.59; N, 13.79 .

\subsubsection{N-(2-Trichloromethylquinazolin-4-yl)propionamide (21)}

Yield 52\%. Yellow solid. Mp $171{ }^{\circ} \mathrm{C}$, (isopropanol). ${ }^{1} \mathrm{H}$ NMR $\left(250 \mathrm{MHz}, \mathrm{DMSO}-d_{6}\right) \delta=11.16$ $(\mathrm{s}, 1 \mathrm{H}), 8.47(\mathrm{~d}, J=7.4 \mathrm{~Hz}, 1 \mathrm{H}), 8.27-7.95(\mathrm{~m}, 2 \mathrm{H}), 7.91-7.68(\mathrm{~m}, 1 \mathrm{H}), 3.03-2.74(\mathrm{~m}, 2 \mathrm{H}), 1.30-1.00$ $(\mathrm{m}, 3 \mathrm{H}) .{ }^{13} \mathrm{C}$ NMR $\left(63 \mathrm{MHz}, \mathrm{DMSO}-d_{6}\right) \delta=175.2,159.3,158.8,149.7,135.4,129.1,128.6,125.0,115.4$, 97.1, 30.4, 9.1. LC-MS (ESI+) $t_{R} 3.39 \mathrm{~min}, \mathrm{~m} / z$ [M + H] $]^{+}$317.98/320.00/322.08. MW: 318.59 g.mol ${ }^{-1}$. HRMS $m / z[\mathrm{M}+\mathrm{H}]^{+}$calcd for $\mathrm{C}_{12} \mathrm{H}_{10} \mathrm{Cl}_{3} \mathrm{~N}_{3} \mathrm{O}: 317.9967$, Found: 317.9964 .

\subsubsection{N-(2-Trichloromethylquinazolin-4-yl)isobutyramide (22)}

Yield 52\%. White solid. Mp $161{ }^{\circ} \mathrm{C}$, (isopropanol). ${ }^{1} \mathrm{H}$ NMR $\left(400 \mathrm{MHz}, \mathrm{DMSO}-d_{6}\right) \delta=11.09(\mathrm{~s}, 1 \mathrm{H})$, $8.34(\mathrm{~d}, J=8.4 \mathrm{~Hz}, 1 \mathrm{H}), 8.09(\mathrm{~d}, J=3.7 \mathrm{~Hz}, 2 \mathrm{H}), 7.88-7.75(\mathrm{~m}, 1 \mathrm{H}), 1.27-1.15(\mathrm{~m}, 7 \mathrm{H}) .{ }^{13} \mathrm{C}$ NMR $(101 \mathrm{MHz}$, DMSO- $_{6}$ ) $\delta=178.0,159.4,159.2,149.8,135.5,129.1,128.6,125.3,116.0,97.1,34.4,19.3$ (2C). LC-MS $\left(\right.$ ESI+) $t_{R} 3.56 \mathrm{~min}, \mathrm{~m} / z[\mathrm{M}+\mathrm{H}]^{+}$332.09/334.97/344.17. MW: $332.61 \mathrm{~g} \cdot \mathrm{mol}^{-1}$. HRMS $m / z[\mathrm{M}+\mathrm{H}]^{+}$calcd for $\mathrm{C}_{13} \mathrm{H}_{12} \mathrm{Cl}_{3} \mathrm{~N}_{3} \mathrm{O}$ : 332.0119, Found: 332.0118 .

\subsubsection{N-(2-Trichloromethylquinazolin-4-yl)pivalamide (23)}

Yield 55\%. White solid. Mp $157^{\circ} \mathrm{C}$, (isopropanol). ${ }^{1} \mathrm{H}$ NMR (400 MHz, DMSO- $\left.d_{6}\right) \delta=10.73(\mathrm{~s}, 1 \mathrm{H})$, 8.17-8.08 (m, 2H), 8.01-7.94 (m, 1H), 7.88-7.80 (m, 1H), $1.39(\mathrm{~s}, 9 \mathrm{H}) .{ }^{13} \mathrm{C}$ NMR (101 MHz, DMSO- $\left.d_{6}\right)$ $\delta=178.0,161.0,159.6,150.1,135.6,129.3,128.5,126.3,118.5,96.9,26.8,26.3$ (3C). LC-MS (ESI+) $t_{R}$ $3.24 \mathrm{~min}, \mathrm{~m} / z[\mathrm{M}+\mathrm{H}]^{+}$346.08/348.13/350.10. MW: 346.64 g. $\mathrm{mol}^{-1}$. HRMS m/z [M+ H] ${ }^{+}$calcd for $\mathrm{C}_{14} \mathrm{H}_{14} \mathrm{Cl}_{3} \mathrm{~N}_{3} \mathrm{O}: 346.0275$, Found: 346.0276 . 


\subsubsection{N-(2-Trichloromethylquinazolin-4-yl)pentanamide (24)}

Yield $43 \%$. Yellow solid. Mp $136{ }^{\circ} \mathrm{C}$, (isopropanol). ${ }^{1} \mathrm{H}$ NMR $\left(400 \mathrm{MHz}, \mathrm{DMSO}-d_{6}\right) \delta=11.16$ $(\mathrm{s}, 1 \mathrm{H}), 8.47(\mathrm{~d}, J=8.4 \mathrm{~Hz}, 1 \mathrm{H}), 8.10-8.04(\mathrm{~m}, 2 \mathrm{H}), 7.88-7.79(\mathrm{~m}, 1 \mathrm{H}), 2.92(\mathrm{t}, J=7.6 \mathrm{~Hz}, 2 \mathrm{H}), 1.65$ $(\mathrm{dt}, J=15.1,7.5 \mathrm{~Hz}, 2 \mathrm{H}), 1.38(\mathrm{dq}, J=14.6,7.3 \mathrm{~Hz}, 2 \mathrm{H}), 0.91(\mathrm{t}, J=7.4 \mathrm{~Hz}, 3 \mathrm{H}) .{ }^{13} \mathrm{C}$ NMR $(101 \mathrm{MHz}$, DMSO- $\left.d_{6}\right) \delta=174.3,159.3,158.8,149.7,135.3,129.0,128.6,125.0,115.4,97.2,36.7,26.6,21.8,13.7$. LC-MS $($ ESI +$) t_{R} 4.26 \mathrm{~min}, m / z[\mathrm{M}+\mathrm{H}]^{+} 346.08 / 348.11 / 349.98$. MW: $346.64 \mathrm{~g} \cdot \mathrm{mol}^{-1}$. HRMS $m / z$ [M + H] $]^{+}$calcd for $\mathrm{C}_{14} \mathrm{H}_{14} \mathrm{Cl}_{3} \mathrm{~N}_{3} \mathrm{O}$ : 346.0275, Found: 346.0274 .

\subsubsection{N-(2-Trichloromethylquinazolin-4-yl)cyclohexanecarboxamide (25)}

Yield 51\%. White solid. Mp $214{ }^{\circ} \mathrm{C}$, (isopropanol). ${ }^{1} \mathrm{H}$ NMR $\left(250 \mathrm{MHz}\right.$, DMSO- $\left.d_{6}\right) \delta=11.05(\mathrm{~s}, 1 \mathrm{H})$, $8.37(\mathrm{~d}, J=8.4 \mathrm{~Hz}, 1 \mathrm{H}), 8.08(\mathrm{~d}, J=3.7 \mathrm{~Hz}, 2 \mathrm{H}), 7.88-7.78(\mathrm{~m}, 1 \mathrm{H}), 2.06-1.92(\mathrm{~m}, 2 \mathrm{H}), 1.84-1.62(\mathrm{~m}, 3 \mathrm{H})$, $1.53-1.18(\mathrm{~m}, 6 \mathrm{H}) .{ }^{13} \mathrm{C}$ NMR $\left(63 \mathrm{MHz}, \mathrm{DMSO}-d_{6}\right) \delta=177.2,167.9,159.2,149.7,135.4,129.1,128.6,125.2$, 115.7, 97.1, 43.8, 28.9 (2C), 25.4, 25.2 (2C). LC-MS (ESI+) $t_{R} 4.58 \mathrm{~min}, \mathrm{~m} / z[\mathrm{M}+\mathrm{H}]^{+} 372.07 / 374.11 / 376.06$. MW: 372.68 g.mol ${ }^{-1}$. HRMS m/z [M + H] $]^{+}$calcd for $\mathrm{C}_{16} \mathrm{H}_{16} \mathrm{Cl}_{3} \mathrm{~N}_{3} \mathrm{O}: 372.0432$, Found: 372.0428 .

\subsection{General Procedure for the Preparation of Compounds (26-44)}

A mixture of 4-chloro-2-trichloromethylquinazoline (4) $(0.2 \mathrm{~g}, 0.71 \mathrm{mmol})$, DMAP (26 mg, $0.21 \mathrm{mmol}, 0.3$ equiv.), and adequate alcohol derivative $(0.85 \mathrm{mmol}, 1.2$ equiv.) in toluene $(3 \mathrm{~mL})$ was placed in a miniaturized sealed reactor $(5 \mathrm{~mL})$. The reaction mixture was irradiated in a monomode microwave oven, for $1 \mathrm{~h}$ at $130{ }^{\circ} \mathrm{C}$. After removal of the toluene under reduced pressure, the residue was purified by silica gel column chromatography and recrystallized from appropriate solvent.

\subsubsection{4-Methoxy-2-Trichloromethylquinazoline (26)}

Yield $81 \%$. White powder. $\mathrm{Mp} 83{ }^{\circ} \mathrm{C}$, (isopropanol). ${ }^{1} \mathrm{H} \mathrm{NMR}\left(200 \mathrm{MHz}, \mathrm{CDCl}_{3}\right) \delta=8.21$ $(\mathrm{d}, J=8 \mathrm{~Hz}, 1 \mathrm{H}), 8.08(\mathrm{~d}, J=8 \mathrm{~Hz}, 1 \mathrm{H}), 7.95-7.87(\mathrm{~m}, 1 \mathrm{H}), 7.70-7.63(\mathrm{~m}, 1 \mathrm{H}), 4.28(\mathrm{~s}, 3 \mathrm{H}) .{ }^{13} \mathrm{C}$ NMR $\left(50 \mathrm{MHz}, \mathrm{CDCl}_{3}\right) \delta=168.1,160.2,150.2,146.6,134.3,128.7,128.5,123.5,97.1,54.9$. LC-MS (ESI+) $t_{R}$ $4.46 \mathrm{~min}, \mathrm{~m} / \mathrm{z}[\mathrm{M}+\mathrm{H}]^{+}$277.05/279.06/281.05. MW: $277.53 \mathrm{~g} / \mathrm{mol}$. Anal. Calcd for $\mathrm{C}_{17} \mathrm{H}_{13} \mathrm{Cl}_{3} \mathrm{~N}_{2} \mathrm{O}: \mathrm{C}$, 43.28; H, 2.54; N, 10.09. Found: C, 44.17; H, 3.14; N, 9.54 .

\subsubsection{4-Ethoxy-2-Trichloromethylquinazoline (27)}

Yield 79\%. White powder. $\mathrm{Mp} 73{ }^{\circ} \mathrm{C}$, (isopropanol). ${ }^{1} \mathrm{H}$ NMR $\left(200 \mathrm{MHz}, \mathrm{CDCl}_{3}\right) \delta=8.23$ $(\mathrm{d}, J=8.2 \mathrm{~Hz}, 1 \mathrm{H}), 8.19(\mathrm{~d}, J=8.2 \mathrm{~Hz}, 1 \mathrm{H}), 7.95-7.85(\mathrm{~m}, 1 \mathrm{H}), 7.68-7.61(\mathrm{~m}, 1 \mathrm{H}), 4.75(\mathrm{q}, J=8 \mathrm{~Hz}$, 2H), $1.55(\mathrm{t}, J=8 \mathrm{~Hz}, 3 \mathrm{H}) .{ }^{13} \mathrm{C}$ NMR $\left(50 \mathrm{MHz}, \mathrm{CDCl}_{3}\right) \delta=167.8,160.3,150.3,134.3,128.7,128.5,123.7$, 115.6, 97.2, 64.1, 14.2. LC-MS (ESI+) $t_{R} 4.92 \mathrm{~min}, \mathrm{~m} / z$ [M + H] ${ }^{+}$290.58/292.58/294.91. MW: $291.56 \mathrm{~g} / \mathrm{mol}$. Anal. Calcd for $\mathrm{C}_{11} \mathrm{H}_{9} \mathrm{Cl}_{3} \mathrm{~N}_{2} \mathrm{O}$ : C, 45.31; $\mathrm{H}, 3.11 ; \mathrm{N}, 9.61$. Found: $\mathrm{C}, 45.16 ; \mathrm{H}, 3.13 ; \mathrm{N}, 9.65$.

\subsubsection{4-Propoxy-2-Trichloromethylquinazoline (28)}

Yield 75\%. Sand powder. Mp $39{ }^{\circ} \mathrm{C}$, (methanol). ${ }^{1} \mathrm{H} \mathrm{NMR}\left(200 \mathrm{MHz}, \mathrm{CDCl}_{3}\right) \delta=8.24(\mathrm{~d}, J=8.2 \mathrm{~Hz}$, $1 \mathrm{H}), 8.07(\mathrm{~d}, J=8.2 \mathrm{~Hz}, 1 \mathrm{H}), 7.94-7.85(\mathrm{~m}, 1 \mathrm{H}), 7.68-7.61(\mathrm{~m}, 1 \mathrm{H}), 4.66(\mathrm{t}, J=7.5 \mathrm{~Hz}, 2 \mathrm{H}), 1.97$ $(\mathrm{q}, J=7.5 \mathrm{~Hz}, 2 \mathrm{H}), 1.12(\mathrm{t}, J=7.5 \mathrm{~Hz}, 3 \mathrm{H}) .{ }^{13} \mathrm{C} \mathrm{NMR}\left(50 \mathrm{MHz}, \mathrm{CDCl}_{3}\right) \delta=167.6,160.0,150.2,134.3,128.7$, 128.5, 123.6, 116.3, 97.2, 69.6, 22.0, 10.6. LC-MS (ESI+) $t_{R} 5.23 \mathrm{~min}, m / z[\mathrm{M}+\mathrm{H}]^{+}$305.05/307.03/309.06. MW: $305.59 \mathrm{~g} / \mathrm{mol}$. Anal. Calcd for $\mathrm{C}_{12} \mathrm{H}_{11} \mathrm{Cl}_{3} \mathrm{~N}_{2} \mathrm{O}$ : C, 47.16; H, 3.63; N, 9.17. Found: C, 46.87; $\mathrm{H}, 3.59$; N, 9.23 .

\subsubsection{4-Butoxy-2-Trichloromethylquinazoline (29)}

Yield 79\%. Yellow oil. ${ }^{1} \mathrm{H}$ NMR $\left(200 \mathrm{MHz}, \mathrm{CDCl}_{3}\right) \delta=8.17(\mathrm{~d}, J=8.2 \mathrm{~Hz}, 1 \mathrm{H}), 8.03(\mathrm{~d}, J=8.2 \mathrm{~Hz}$, $1 \mathrm{H}), 7.90-7.80(\mathrm{~m}, 1 \mathrm{H}), 7.65-7.57(\mathrm{~m}, 1 \mathrm{H}), 4.68(\mathrm{t}, J=4.6 \mathrm{~Hz}, 2 \mathrm{H}), 1.97-1.83(\mathrm{~m}, 2 \mathrm{H}), 1.64-1.46(\mathrm{~m}, 2 \mathrm{H}), 1.01$ $(\mathrm{t}, J=7.4 \mathrm{~Hz}, 3 \mathrm{H}) .{ }^{13} \mathrm{C} \mathrm{NMR}\left(50 \mathrm{MHz}, \mathrm{CDCl}_{3}\right) \delta=167.9,160.3,150.2,134.2,128.6,128.5,123.6,115.5,97.3$, 
67.9, 30.7,19.3, 13.9. LC-MS (ESI+) $t_{R} 5.42 \mathrm{~min}, \mathrm{~m} / \mathrm{z}[\mathrm{M}+\mathrm{H}]^{+}$318.85/320.96/322.47. MW: $319.61 \mathrm{~g} / \mathrm{mol}$. Anal. Calcd for $\mathrm{C}_{13} \mathrm{H}_{13} \mathrm{Cl}_{3} \mathrm{~N}_{2}$ : C, 48.85; $\mathrm{H}, 4.10 ; \mathrm{N}$, 8.76. Found: $\mathrm{C}, 49.12 ; \mathrm{H}, 4.04 ; \mathrm{N}, 8.65$.

3.6.5. 4-Isopropoxy-2-Trichloromethylquinazoline (30)

Yield 53\%. Grey powder. Mp $210{ }^{\circ} \mathrm{C}$, (methanol). ${ }^{1} \mathrm{H} \mathrm{NMR}\left(200 \mathrm{MHz}, \mathrm{CDCl}_{3}\right) \delta=8.20(\mathrm{~d}, J=8.2 \mathrm{~Hz}$, $1 \mathrm{H}), 8.05(\mathrm{~d}, J=8.2 \mathrm{~Hz}, 1 \mathrm{H}), 7.93-7.85(\mathrm{~m}, 1 \mathrm{H}), 7.68-7.60(\mathrm{~m}, 1 \mathrm{H}), 5.69(\mathrm{t}, J=6 \mathrm{~Hz}, 1 \mathrm{H}), 1.52(\mathrm{~d}, J=6 \mathrm{~Hz}$, $6 \mathrm{H}) .{ }^{13} \mathrm{C}$ NMR $\left(50 \mathrm{MHz}, \mathrm{CDCl}_{3}\right) \delta=167.4,160.4,150.3,134.2,128.7,128.4,123.7,115.8,97.3,71.8,21.7$. LC-MS (ESI+) $t_{R} 5.24 \mathrm{~min}, m / z$ [M + H] $305.04 / 307.05 / 309.10$. MW: $305.59 \mathrm{~g} / \mathrm{mol}$. Anal. Calcd for $\mathrm{C}_{12} \mathrm{H}_{11} \mathrm{Cl}_{3} \mathrm{~N}_{2} \mathrm{O}: \mathrm{C}, 47.16 ; \mathrm{H}, 3.63 ; \mathrm{N}, 9.17$. Found: $\mathrm{C}, 46.81 ; \mathrm{H}, 3.72 ; \mathrm{N}, 9.39$.

3.6.6. 4-(Prop-2-ynyloxy)-2-Trichloromethylquinazoline (31)

Yield $87 \%$. Beige powder. $\mathrm{Mp} 62^{\circ} \mathrm{C}$, (methanol). ${ }^{1} \mathrm{H} \mathrm{NMR}\left(200 \mathrm{MHz}, \mathrm{CDCl}_{3}\right) \delta=8.26(\mathrm{~d}, J=8.2 \mathrm{~Hz}$, $1 \mathrm{H}), 8.10(\mathrm{~d}, J=8.2 \mathrm{~Hz}, 1 \mathrm{H}), 7.97-7.89(\mathrm{~m}, 1 \mathrm{H}), 7.73-7.65(\mathrm{~m}, 1 \mathrm{H}), 5.31(\mathrm{~d}, J=2.5 \mathrm{~Hz}, 2 \mathrm{H}), 2.58(\mathrm{t}, J=2.5 \mathrm{~Hz}$, 1H). ${ }^{13} \mathrm{C}$ NMR $\left(50 \mathrm{MHz}, \mathrm{CDCl}_{3}\right) \delta=166.7,159.8,150.4,134.7,128.9,128.8,123.6,115.2,96.9,77.4,75.7$, 55.3. LC-MS (ESI+) $t_{R} 4.42 \mathrm{~min}, m / z[\mathrm{M}+\mathrm{H}]^{+} 301.02 / 303.03 / 305.04$. MW: $301.56 \mathrm{~g} / \mathrm{mol}$. Anal. Calcd for $\mathrm{C}_{12} \mathrm{H}_{7} \mathrm{Cl}_{3} \mathrm{~N}_{2} \mathrm{O}$ : C, 47.79; $\mathrm{H}, 2.34 ; \mathrm{N}, 9.29$. Found: C, 48.38; $\mathrm{H}, 2.25 ; \mathrm{N}, 9.08$.

3.6.7. 4-(But-3-yn-2-yloxy)-2-Trichloromethylquinazoline (32)

Yield $89 \%$. Beige powder. Mp $92{ }^{\circ} \mathrm{C}$, (methanol). ${ }^{1} \mathrm{H} \mathrm{NMR}\left(200 \mathrm{MHz}, \mathrm{CDCl}_{3}\right) \delta=8.26(\mathrm{~d}, J=8.2 \mathrm{~Hz}$, $1 \mathrm{H}), 8.09(\mathrm{~d}, J=8.2 \mathrm{~Hz}, 1 \mathrm{H}), 7.96-7.91(\mathrm{~m}, 1 \mathrm{H}), 7.72-7.64(\mathrm{~m}, 1 \mathrm{H}), 6.18(\mathrm{qd}, J=8 \mathrm{~Hz}, J=2 \mathrm{~Hz}, 1 \mathrm{H})$, $2.52(\mathrm{~d}, J=2 \mathrm{~Hz}, 1 \mathrm{H}), 1.80(\mathrm{~d}, J=8 \mathrm{~Hz}, 3 \mathrm{H}) .{ }^{13} \mathrm{C} \mathrm{NMR}\left(50 \mathrm{MHz}, \mathrm{CDCl}_{3}\right) \delta=166.4,159.9,150.5$, 134.6, 128.8, 128.7, 123.7, 115.4, 97.0, 81.9, 73.7, 63.7, 21.2. LC-MS (ESI+) $t_{R} 4.73 \mathrm{~min}, \mathrm{~m} / z[\mathrm{M}+\mathrm{H}]^{+}$ 315.02/317.04/318.98. MW: $315.58 \mathrm{~g} / \mathrm{mol}$. Anal. Calcd for $\mathrm{C}_{13} \mathrm{H}_{9} \mathrm{Cl}_{3} \mathrm{~N}_{2} \mathrm{O}: \mathrm{C}, 49.48 ; \mathrm{H}, 2.87 ; \mathrm{N}, 8.88$. Found: C, 48.96; H, 2.95; N, 8.93 .

3.6.8. 4-(4-Methylpent-1-yn-3-yloxy)-2-Trichloromethylquinazoline (33)

Yield 90\%. Beige powder. Mp $96{ }^{\circ} \mathrm{C}$, (methanol). ${ }^{1} \mathrm{H}$ NMR $\left(200 \mathrm{MHz}, \mathrm{CDCl}_{3}\right) \delta=8.30-8.27$ $(\mathrm{m}, 1 \mathrm{H}), 8.09(\mathrm{~d}, J=8.2 \mathrm{~Hz}, 1 \mathrm{H}), 7.97-7.88(\mathrm{~m}, 1 \mathrm{H}), 7.72-7.64(\mathrm{~m}, 1 \mathrm{H}), 5.97(\mathrm{dd}, J=6 \mathrm{~Hz}, J=2 \mathrm{~Hz}$, $1 \mathrm{H}), 2.49(\mathrm{~d}, J=2 \mathrm{~Hz}, 1 \mathrm{H}), 2.44-2.28(\mathrm{~m}, 1 \mathrm{H}), 1.20(\mathrm{~d}, J=4 \mathrm{~Hz}, 3 \mathrm{H}), 1.17(\mathrm{~d}, J=4 \mathrm{~Hz}, 3 \mathrm{H}) .{ }^{13} \mathrm{C} \mathrm{NMR}$ $\left(50 \mathrm{MHz}, \mathrm{CDCl}_{3}\right) \delta=166.7,160.0,150.6,134.6,128.8,128.7,123.6,115.5,97.0,79.5,74.9,72.1,32.4,18.2$, 17.6. LC-MS (ESI+) $t_{R} 5.21 \mathrm{~min}, \mathrm{~m} / z$ [M $\left.+\mathrm{H}\right]^{+} 343.17 / 345.22 / 347.09$. MW: $343.64 \mathrm{~g} / \mathrm{mol}$. Anal. Calcd for $\mathrm{C}_{15} \mathrm{H}_{13} \mathrm{Cl}_{3} \mathrm{~N}_{2} \mathrm{O}: \mathrm{C}, 52.43 ; \mathrm{H}, 3.81 ; \mathrm{N}, 8.15$. Found: $\mathrm{C}, 53.02 ; \mathrm{H}, 3.75 ; \mathrm{N}, 8.37$.

3.6.9. 2-(2-Trichloromethylquinazolin-4-yloxy)ethanol (34)

Yield $42 \%$. White powder. Mp $93{ }^{\circ} \mathrm{C}$, (methanol). ${ }^{1} \mathrm{H}$ NMR $\left(200 \mathrm{MHz}, \mathrm{CDCl}_{3}\right) \delta=8.31-8.28$ $(\mathrm{m}, 1 \mathrm{H}), 8.15(\mathrm{~d}, J=8.2 \mathrm{~Hz}, 1 \mathrm{H}), 8.01-7.93(\mathrm{~m}, 1 \mathrm{H}), 7.78-7.70(\mathrm{~m}, 1 \mathrm{H}), 4.94-4.91(\mathrm{~m}, 2 \mathrm{H}), 4.21-4.17$ (m, 2H), 2.49 (br s, 1H). ${ }^{13} \mathrm{C}$ NMR $\left(50 \mathrm{MHz}, \mathrm{CDCl}_{3}\right) \delta=168.1,159.8,150.3,134.8,129.0,128.8,123.7$, 115.4, 97.1, 70.1, 61.8. LC-MS (ESI+) $t_{R} 3.33 \mathrm{~min}, \mathrm{~m} / z$ [M + H] ${ }^{+}$306.93/308.91/311.07. MW: $307.56 \mathrm{~g} / \mathrm{mol}$. Anal. Calcd for $\mathrm{C}_{11} \mathrm{H}_{9} \mathrm{Cl}_{3} \mathrm{~N}_{2} \mathrm{O}: \mathrm{C}, 42.96 ; \mathrm{H}, 2.95 ; \mathrm{N}, 9.11$. Found: $\mathrm{C}, 43.71 ; \mathrm{H}, 3.03 ; \mathrm{N}, 8.95$.

3.6.10. 4-(2-Methoxyethoxy)-2-Trichloromethylquinazoline (35)

Yield 97\%. White powder. Mp $63{ }^{\circ} \mathrm{C}$, (methanol). ${ }^{1} \mathrm{H}$ NMR $\left(200 \mathrm{MHz}, \mathrm{CDCl}_{3}\right) \delta=8.31(\mathrm{~d}, J=8 \mathrm{~Hz}$, $1 \mathrm{H}), 8.15(\mathrm{~d}, J=8 \mathrm{~Hz}, 1 \mathrm{H}), 7.91(\mathrm{t}, J=6 \mathrm{~Hz}, 1 \mathrm{H}), 7.66(\mathrm{t}, J=6 \mathrm{~Hz}, 1 \mathrm{H}), 4.87-4.83(\mathrm{~m}, 2 \mathrm{H}), 3.92-3.88$ $(\mathrm{m}, 2 \mathrm{H}), 3.47(\mathrm{~s}, 3 \mathrm{H}) .{ }^{13} \mathrm{C}$ NMR $\left(50 \mathrm{MHz}, \mathrm{CDCl}_{3}\right) \delta=167.7,160.2,150.6,134.2,128.8,128.4,123.7,115.5$, 97.2, 70.4, 66.9, 59.0. LC-MS (ESI+) $t_{R} 4.28 \mathrm{~min}, \mathrm{~m} / z[\mathrm{M}+\mathrm{H}]^{+} 321.00 / 322.91 / 325.13$. MW: $321.59 \mathrm{~g} / \mathrm{mol}$. Anal. Calcd for $\mathrm{C}_{12} \mathrm{H}_{11} \mathrm{Cl}_{3} \mathrm{~N}_{2} \mathrm{O}: \mathrm{C}, 44.82 ; \mathrm{H}, 3.45 ; \mathrm{N}, 8.71$. Found: $\mathrm{C}, 44.35 ; \mathrm{H}, 3.38 ; \mathrm{N}, 8.92$. 
3.6.11. 4-(2-Chloroethoxy)-2-Trichloromethylquinazoline (36)

Yield 79\%. Sand powder. Mp $54{ }^{\circ} \mathrm{C}$, (methanol). ${ }^{1} \mathrm{H}$ NMR $\left(200 \mathrm{MHz}, \mathrm{CDCl}_{3}\right) \delta=8.26(\mathrm{~d}, J=8 \mathrm{~Hz}$, $1 \mathrm{H}), 8.09(\mathrm{~d}, J=8 \mathrm{~Hz}, 1 \mathrm{H}), 7.97-7.89(\mathrm{~m}, 1 \mathrm{H}), 7.73-7.65(\mathrm{~m}, 1 \mathrm{H}), 4.94(\mathrm{t}, J=6 \mathrm{~Hz}, 2 \mathrm{H}), 4.00(\mathrm{t}, J=6 \mathrm{~Hz}$, 2H). ${ }^{13} \mathrm{C} \mathrm{NMR}\left(50 \mathrm{MHz}, \mathrm{CDCl}_{3}\right) \delta=167.3,159.9,150.4,134.7,128.9,128.8,123.6,115.2,96.9,67.4,41.4$. LC-MS (ESI+) $t_{R} 4.60 \mathrm{~min}, m / z[\mathrm{M}+\mathrm{H}]^{+} 325.03 / 327.01 / 329.07$. MW: $326.01 \mathrm{~g} / \mathrm{mol}$. Anal. Calcd for $\mathrm{C}_{11} \mathrm{H}_{8} \mathrm{Cl}_{4} \mathrm{~N}_{2} \mathrm{O}: \mathrm{C}, 40.53 ; \mathrm{H}, 2.47 ; \mathrm{N}, 8.59$. Found: C, 43.89; H, 3.45; N, 9.02.

3.6.12. 4-(3-Chloropropoxy)-2-Trichloromethylquinazoline (37)

Yield 70\%. Beige powder. Mp $77^{\circ} \mathrm{C}$, (methanol). ${ }^{1} \mathrm{H} \mathrm{NMR}\left(200 \mathrm{MHz}, \mathrm{CDCl}_{3}\right) \delta=8.22(\mathrm{~d}, J=8 \mathrm{~Hz}$, $1 \mathrm{H}), 8.08(\mathrm{~d}, J=8 \mathrm{~Hz}, 1 \mathrm{H}), 7.96-7.88(\mathrm{~m}, 1 \mathrm{H}), 7.71-7.64(\mathrm{t}, J=6 \mathrm{~Hz}, 1 \mathrm{H}), 4.86(\mathrm{t}, J=6 \mathrm{~Hz}, 2 \mathrm{H}), 3.79$ $(\mathrm{t}, J=6 \mathrm{~Hz}, 2 \mathrm{H}), 2.42(\mathrm{t}, J=6 \mathrm{~Hz}, 2 \mathrm{H}) .{ }^{13} \mathrm{C}$ NMR $\left(50 \mathrm{MHz}, \mathrm{CDCl}_{3}\right) \delta=167.6,160.1,150.3,134.5,128.9$, $128.7,123.5,115.4,97.1,64.7,41.3$, 31.6. LC-MS (ESI+) $t_{R} 4.89 \mathrm{~min}, m / z[\mathrm{M}+\mathrm{H}]^{+} 339.04 / 341.06 / 343.09$. MW: $340.03 \mathrm{~g} / \mathrm{mol}$. Anal. Calcd for $\mathrm{C}_{12} \mathrm{H}_{10} \mathrm{Cl}_{4} \mathrm{~N}_{2} \mathrm{O}$ : C, 42.39; $\mathrm{H}, 2.96 ; \mathrm{N}, 8.24$. Found: $\mathrm{C}, 42.06 ; \mathrm{H}, 3.01$; $\mathrm{N}, 8.51$.

3.6.13. 4-(4-Chlorobutoxy)-2-Trichloromethylquinazoline (38)

Yield $28 \%$. Yellow oil. ${ }^{1} \mathrm{H}$ NMR $\left(200 \mathrm{MHz}, \mathrm{CDCl}_{3}\right) \delta=8.20(\mathrm{~d}, J=8 \mathrm{~Hz}, 1 \mathrm{H}), 8.07(\mathrm{~d}, J=8 \mathrm{~Hz}, 1 \mathrm{H})$, 7.95-7.87 (m, 1H), $7.66(\mathrm{t}, J=6 \mathrm{~Hz}, 1 \mathrm{H}), 4.74(\mathrm{t}, J=6 \mathrm{~Hz}, 2 \mathrm{H}), 3.66(\mathrm{t}, J=6 \mathrm{~Hz}, 2 \mathrm{H}), 2.00-2.15(\mathrm{~m}, 4 \mathrm{H})$. ${ }^{13} \mathrm{C} \mathrm{NMR}\left(50 \mathrm{MHz}, \mathrm{CDCl}_{3}\right) \delta=167.7,160.2,150.3,134.4,128.8,128.7,123.5,115.4,97.2,67.2,44.6,29.3$, 26.1. LC-MS (ESI+) $t_{R} 5.09 \mathrm{~min}, \mathrm{~m} / z$ [M + H] $]^{+} 352.94 / 354.55 / 357.10$. MW: $354.06 \mathrm{~g} / \mathrm{mol}$. Anal. Calcd for $\mathrm{C}_{13} \mathrm{H}_{12} \mathrm{Cl}_{4} \mathrm{~N}_{2} \mathrm{O}: \mathrm{C}, 44.10 ; \mathrm{H}, 3.42 ; \mathrm{N}, 7.91$. Found: $\mathrm{C}, 43.87 ; \mathrm{H}, 3.39 ; \mathrm{N}, 8.02$.

3.6.14. 4-(2-Fluoroethoxy)-2-Trichloromethylquinazoline (39)

Yield 71\%. Off-white powder. Mp $73{ }^{\circ} \mathrm{C}$, (isopropanol). ${ }^{1} \mathrm{H}$ NMR $\left(200 \mathrm{MHz}, \mathrm{CDCl}_{3}\right) \delta=8.22$ $(\mathrm{d}, J=8 \mathrm{~Hz}, 1 \mathrm{H}), 8.05(\mathrm{~d}, J=8 \mathrm{~Hz}, 1 \mathrm{H}), 7.92-7.86(\mathrm{~m}, 1 \mathrm{H}), 7.64(\mathrm{t}, J=6 \mathrm{~Hz}, 1 \mathrm{H}), 5.00(\mathrm{~s}, 2 \mathrm{H}), 4.81-4.89$ (m, 2H). ${ }^{13} \mathrm{C} \mathrm{NMR}\left(50 \mathrm{MHz}, \mathrm{CDCl}_{3}\right) \delta=167.3,159.8,150.3,134.7,128.8,128.7,123.6,115.2,97.1,81.2$ $(\mathrm{d}, J \mathrm{C}-\mathrm{F}=171 \mathrm{~Hz}), 66.8(\mathrm{~d}, J \mathrm{C}-\mathrm{F}=21 \mathrm{~Hz})$. LC-MS $(\mathrm{ESI}+) t_{R} 4.17 \mathrm{~min}, m / z[\mathrm{M}+\mathrm{H}]^{+}$309.15/311.13/313.16. MW: $309.55 \mathrm{~g} / \mathrm{mol}$. Anal. Calcd for $\mathrm{C}_{11} \mathrm{H}_{8} \mathrm{Cl}_{3} \mathrm{FN}_{2} \mathrm{O}: \mathrm{C}, 42.68 ; \mathrm{H}, 2.60 ; \mathrm{N}, 9.05$. Found: $\mathrm{C}, 42.87 ; \mathrm{H}, 2.55$; N, 8.93 .

3.6.15. 4-(2-Bromoethoxy)-2-Trichloromethylquinazoline (40)

Yield 71\%. Beige powder. Mp $100{ }^{\circ} \mathrm{C}$, (isopropanol). ${ }^{1} \mathrm{H}$ NMR $\left(200 \mathrm{MHz}, \mathrm{CDCl}_{3}\right) \delta=8.30$ $(\mathrm{d}, J=8 \mathrm{~Hz}, 1 \mathrm{H}), 7.84-7.83(\mathrm{~m}, 2 \mathrm{H}), 7.66-7.61(\mathrm{~m}, 1 \mathrm{H}), 4.85-4.78(\mathrm{~m}, 2 \mathrm{H}), 3.92-3.85(\mathrm{~m}, 2 \mathrm{H}) .{ }^{13} \mathrm{C}$ NMR $\left(50 \mathrm{MHz}, \mathrm{CDCl}_{3}\right) \delta=162.6,147.6,144.1,135.2,129.4,128.8,127.1,102.6,93.4,47.7,38.8$. LC-MS (ESI+) $t_{R} 4.73 \mathrm{~min}, \mathrm{~m} / \mathrm{z}[\mathrm{M}+\mathrm{H}]^{+} 369.12 / 370.96 / 373.11$. MW: $370.46 \mathrm{~g} / \mathrm{mol}$. Anal. Calcd for $\mathrm{C}_{11} \mathrm{H}_{8} \mathrm{BrCl}_{3} \mathrm{~N}_{2} \mathrm{O}: \mathrm{C}$, 35.66; H, 2.18; N, 7.56. Found: C, 35.92; H, 2.29; N, 7.37.

3.6.16. N,N-Diethyl-2-[(2-Trichloromethylquinazolin-4-yl)oxy]ethanamine (41)

Yield $67 \%$. Off-white powder. Mp $137{ }^{\circ} \mathrm{C}$, (isopropanol). ${ }^{1} \mathrm{H} \mathrm{NMR}\left(200 \mathrm{MHz}, \mathrm{CDCl}_{3}\right) \delta=8.24$ $(\mathrm{d}, J=8 \mathrm{~Hz}, 1 \mathrm{H}), 8.21-8.20(\mathrm{~m}, 1 \mathrm{H}), 8.10-8.06(\mathrm{~m}, 1 \mathrm{H}), 7.71-7.67(\mathrm{~m}, 1 \mathrm{H}), 4.77(\mathrm{t}, J=6 \mathrm{~Hz}, 4 \mathrm{H}), 3.02$ $(\mathrm{t}, J=6 \mathrm{~Hz}, 4 \mathrm{H}), 2.69(\mathrm{q}, J=7 \mathrm{~Hz}, 4 \mathrm{H}), 1.09(\mathrm{t}, J=7 \mathrm{~Hz}, 6 \mathrm{H}) .{ }^{13} \mathrm{C} \mathrm{NMR}\left(50 \mathrm{MHz}, \mathrm{CDCl}_{3}\right) \delta=167.8,160.3$, 150.6, 134.2, 128.8, 128.4, 123.6, 115.5, 97.3, 66.2, 51.1, 48.0, 11.9. LC-MS (ESI+) $t_{R} 4.53 \mathrm{~min}, \mathrm{~m} / z$ [M + H] ${ }^{+}$ 362.17/364.21/366.18. MW: $362.68 \mathrm{~g} / \mathrm{mol}$. Anal. Calcd for $\mathrm{C}_{15} \mathrm{H}_{18} \mathrm{Cl}_{3} \mathrm{~N}_{3} \mathrm{O}: \mathrm{C}, 49.67 ; \mathrm{H}, 5.00 ; \mathrm{N}, 11.59$. Found: C, 49.19; H, 5.11; N, 11.75 .

3.6.17. N-\{2-[(2-Trichloromethylquinazolin-4-yl)oxy]ethyl\}acetamide (42)

Yield 79\%. White powder. Mp $135{ }^{\circ} \mathrm{C}$, (isopropanol). ${ }^{1} \mathrm{H}$ NMR $\left(200 \mathrm{MHz}, \mathrm{CDCl}_{3}\right) \delta=8.27$ $(\mathrm{d}, J=8 \mathrm{~Hz}, 1 \mathrm{H}), 8.13(\mathrm{~d}, J=8 \mathrm{~Hz}, 1 \mathrm{H}), 7.99(\mathrm{t}, J=7 \mathrm{~Hz}, 1 \mathrm{H}), 7.74(\mathrm{t}, J=7 \mathrm{~Hz}, 1 \mathrm{H}), 6.61(\mathrm{br} \mathrm{s}, 1 \mathrm{H}), 4.87$ $(\mathrm{t}, J=5 \mathrm{~Hz}, 2 \mathrm{H}), 3.88(\mathrm{~d}, J=5 \mathrm{~Hz}, 2 \mathrm{H}), 2.07(\mathrm{~s}, 3 \mathrm{H}) .{ }^{13} \mathrm{C} \mathrm{NMR}\left(50 \mathrm{MHz}, \mathrm{CDCl}_{3}\right) \delta=171.9,167.2,159.8$, 
$150.3,134.8,129.0,128.8,123.7,115.2,97.0,66.4,39.6,22.6$. LC-MS (ESI+) $t_{R} 3.38 \mathrm{~min}, m / z[\mathrm{M}+\mathrm{H}]^{+}$ 348.22/350.14/351.93. MW: 348.61 g/mol. Anal. Calcd for $\mathrm{C}_{13} \mathrm{H}_{12} \mathrm{Cl}_{3} \mathrm{~N}_{3} \mathrm{O}_{2}: \mathrm{C}, 44.79 ; \mathrm{H}, 3.47 ; \mathrm{N}, 12.05$. Found: C, 45.23; H, 3.39; N, 12.35 .

3.6.18. 4-[2-(Piperidin-1-yl)ethoxy]-2-Trichloromethylquinazoline (43)

Yield 20\%. Yellow oil. ${ }^{1} \mathrm{H}$ NMR $\left(200 \mathrm{MHz}, \mathrm{CDCl}_{3}\right) \delta=8.13-8.26(\mathrm{~m}, 1 \mathrm{H}), 7.99-8.11(\mathrm{~m}, 1 \mathrm{H})$, 7.76-7.99 (m, 1H), 7.57-7.74 (m,1H), $4.82(\mathrm{t}, J=6.1 \mathrm{~Hz}, 2 \mathrm{H}), 2.91(\mathrm{t}, J=6.1 \mathrm{~Hz}, 2 \mathrm{H}), 2.49-2.62(\mathrm{~m}, 4 \mathrm{H})$, 1.50-1.69 (m, 4H), $1.42(\mathrm{dt}, J=19.8,7.3 \mathrm{~Hz}, 2 \mathrm{H}) .{ }^{13} \mathrm{C} \mathrm{NMR}\left(50 \mathrm{MHz}, \mathrm{CDCl}_{3}\right) \delta=167.8,160.3,150.4$,

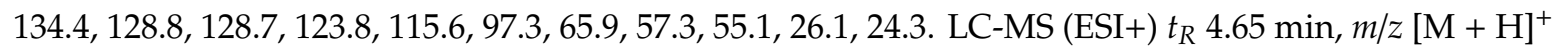
374.05/376.08/378.05. MW: $374.69 \mathrm{~g} / \mathrm{mol}$. HRMS m/z $[\mathrm{M}+\mathrm{H}]^{+}$calcd for $\mathrm{C}_{16} \mathrm{H}_{18} \mathrm{Cl}_{3} \mathrm{~N}_{3} \mathrm{O}: 374.0588$, found: 374.0588 .

3.6.19. 4-[2-(Pyrrolidin-1-yl)ethoxy]-2-Trichloromethylquinazoline (44)

Yield 47\%. Yellow oil. ${ }^{1} \mathrm{H}$ NMR $\left(200 \mathrm{MHz}, \mathrm{CDCl}_{3}\right) \delta=8.25(\mathrm{~d}, J=8.3 \mathrm{~Hz}, 1 \mathrm{H}), 8.07(\mathrm{~d}, J=8.3 \mathrm{~Hz}$, $1 \mathrm{H}), 7.84-7.97(\mathrm{~m}, 1 \mathrm{H}), 7.58-7.78(\mathrm{~m}, 1 \mathrm{H}), 5.02(\mathrm{t}, J=5.5 \mathrm{~Hz}, 2 \mathrm{H}), 3.33(\mathrm{t}, J=5.5 \mathrm{~Hz}, 2 \mathrm{H}), 2.91-3.18$ $(\mathrm{m}, 4 \mathrm{H}), 1.82-2.09(\mathrm{~m}, 4 \mathrm{H}) .{ }^{13} \mathrm{C} \mathrm{NMR}\left(50 \mathrm{MHz}, \mathrm{CDCl}_{3}\right) \delta=167.3,159.9,150.4,134.8,129.1,128.9,123.7$, $115.3,97.1,64.9,54.7,53.7,23.5$. LC-MS (ESI+) $t_{R} 3.77 \mathrm{~min}, m / z[\mathrm{M}+\mathrm{H}]^{+} 360.03 / 362.15 / 364.10$. MW: $360.67 \mathrm{~g} / \mathrm{mol}$. HRMS m/z [M + H] $]^{+}$calcd for $\mathrm{C}_{15} \mathrm{H}_{16} \mathrm{Cl}_{3} \mathrm{~N}_{3} \mathrm{O}: 360.0432$, found: 360.0429 .

\subsection{General Procedure for the Preparation of Compounds (45-46)}

To a solution of 4 -methoxybenzamide (1.5 equiv.) in dry DMF $(3 \mathrm{~mL})$ at $0{ }^{\circ} \mathrm{C}$ under $\mathrm{N}_{2}, 60 \%$ sodium hydride in oil (1.5 equiv.) were added portion wise. The resulting mixture were added dropwise to a solution of 4-chloro-2-methylquinazoline or 4-chloro-2-trifluoromethylquinazoline (200 mg, 1.0 equiv.) in dry DMF $(2 \mathrm{~mL})$ at $0{ }^{\circ} \mathrm{C}$ under $\mathrm{N}_{2}$. The reaction was stirred overnight at $\mathrm{rt}$. Then, the excess of $\mathrm{NaH}$ was hydrolyzed with ice. The reaction mixture was extracted with EtOAc and washed three times with brine. The organic layer was dried with $\mathrm{Na}_{2} \mathrm{SO}_{4}$, filtered and concentrated. The crude product was purified by silica gel column chromatography and recrystallized from isopropanol to give the corresponding compound.

\subsubsection{4-methoxy-N-(2-Methylquinazolin-4-yl)benzamide (45)}

Yield 15\%. Yellow solid. Mp $169^{\circ} \mathrm{C}$, (isopropanol). ${ }^{1} \mathrm{H} \mathrm{NMR}\left(400 \mathrm{MHz}, \mathrm{CDCl}_{3}\right) \delta=14.96(\mathrm{~s}, 1 \mathrm{H})$, $8.71(\mathrm{~d}, J=7.7 \mathrm{~Hz}, 1 \mathrm{H}), 8.39(\mathrm{~d}, J=8.7 \mathrm{~Hz}, 2 \mathrm{H}), 7.87-7.78(\mathrm{~m}, 1 \mathrm{H}), 7.72(\mathrm{~d}, J=8.1 \mathrm{~Hz}, 1 \mathrm{H}), 7.60-7.52$ $(\mathrm{m}, 1 \mathrm{H}), 6.98(\mathrm{~d}, J=8.9 \mathrm{~Hz}, 2 \mathrm{H}), 3.89(\mathrm{~s}, 3 \mathrm{H}), 2.63(\mathrm{~s}, 3 \mathrm{H}) .{ }^{13} \mathrm{C} \mathrm{NMR}\left(101 \mathrm{MHz}, \mathrm{CDCl}_{3}\right) \delta 179.7,163.2$, $158.1,150.9,148.8,135.1,131.9,130.0,127.1,126.1,119.8,113.5(4 C), 55.4,22.8$. LC-MS (ESI+) $t_{R} 2.58 \mathrm{~min}$, $m / z[\mathrm{M}+\mathrm{H}]^{+}$294.10. MW: $293.32 \mathrm{~g} \cdot \mathrm{mol}^{-1}$. HRMS $m / z[\mathrm{M}+\mathrm{H}]^{+}$calcd for $\mathrm{C}_{17} \mathrm{H}_{15} \mathrm{~N}_{3} \mathrm{O}_{2}:$ 294.1237, Found: 294.1234 .

\subsubsection{4-methoxy-N-(2-Trifluoromethylquinazolin-4-yl)benzamide (46)}

Yield 17\%. White solid. Mp $190{ }^{\circ} \mathrm{C}$, (isopropanol). ${ }^{1} \mathrm{H}$ NMR $\left(400 \mathrm{MHz}, \mathrm{DMSO}-d_{6}\right) \delta=11.53(\mathrm{~s}, 1 \mathrm{H})$, $8.26(\mathrm{~d}, J=8.4 \mathrm{~Hz}, 1 \mathrm{H}), 8.20-8.10(\mathrm{~m}, 2 \mathrm{H}), 8.07(\mathrm{~d}, J=8.9 \mathrm{~Hz}, 2 \mathrm{H}), 7.90-7.81(\mathrm{~m}, 1 \mathrm{H}), 7.11(\mathrm{~d}, J=8.9 \mathrm{~Hz}$, 2H), $3.87(\mathrm{~s}, 3 \mathrm{H}) .{ }^{13} \mathrm{C}$ NMR $\left(101 \mathrm{MHz}, \mathrm{DMSO}-d_{6}\right) \delta 166.68,162.99,161.01,150.71(\mathrm{q}, J=35.6 \mathrm{~Hz}), 150.38$, 135.65, 130.98 (2C), 129.41, 128.46, 126.39, 125.06, 119.79 (q, J = 275.6 Hz), 118.76, $113.80(2 \mathrm{C}), 55.57$. LC-MS (ESI+) $t_{R} 2.53 \mathrm{~min}, \mathrm{~m} / z[\mathrm{M}+\mathrm{H}]^{+}$348.29. MW: $347.29 \mathrm{~g} \cdot \mathrm{mol}^{-1}$. HRMS m/z [M + H] ${ }^{+}$calcd for $^{2}$ $\mathrm{C}_{17} \mathrm{H}_{12} \mathrm{~F}_{3} \mathrm{~N}_{3} \mathrm{O}_{2}$ : 348.0954, Found: 348.0953 .

\subsection{General Procedure for the Preparation of Compounds (47-49)}

A mixture of 4-chloro-2-methylquinazoline, 4-chloro-2-trifluoromethylquinazoline or 4-chloroquinazoline (400 mg, 1 equiv.), DMAP (1.1 equiv) and 2-(diethylamino)ethanol (2 equiv.) in toluene $(3 \mathrm{~mL})$ was placed in a miniaturized sealed reactor $(5 \mathrm{~mL})$. The reaction mixture was irradiated 
in a monomode microwave oven, for $1 \mathrm{~h}$ at $130{ }^{\circ} \mathrm{C}$. After removal of the toluene under reduced pressure, the residue was purified by silica gel column chromatography, deactivated by triethylamine, and recrystallized from isopropanol.

3.8.1. N,N-Diethyl-2-[(2-Methylquinazolin-4-yl)oxy]ethanamine (47)

Yield 39\%. Yellow powder. Mp $230{ }^{\circ} \mathrm{C}$, (isopropanol). ${ }^{1} \mathrm{H} \mathrm{NMR}\left(200 \mathrm{MHz}, \mathrm{CDCl}_{3}\right) \delta=7.98-7.95$ $(\mathrm{m}, 1 \mathrm{H}), 7.73-7.62(\mathrm{~m}, 2 \mathrm{H}), 7.35-7.29(1 \mathrm{H}, \mathrm{m}), 4.55-4.51(2 \mathrm{H}, \mathrm{m}), 2.89-2.84(2 \mathrm{H}, \mathrm{m}), 2.61-2.53(7 \mathrm{H}, \mathrm{m})$, 1.02-0.97 (6H, m). 13C NMR (50 MHz, $\left.\mathrm{CDCl}_{3}\right) \delta=166.2,163.6,151.2,133.1,126.7,125.8,123.2,114.4$, $64.9,50.8,47.8(2 \mathrm{C}), 26.2,11.9(2 \mathrm{C})$. LC-MS (ESI+) $t_{R} 1.82 \mathrm{~min}, \mathrm{~m} / z$ [M + H] ${ }^{+}$260.55. MW: $259.35 \mathrm{~g} / \mathrm{mol}$. Anal. Calcd for $\mathrm{C}_{15} \mathrm{H}_{21} \mathrm{~N}_{3} \mathrm{O}$ : C, 69.47; H, 8.16; N, 16.20. Found: C, 70.05; H, 8.07; N, 16.39.

3.8.2. N,N-Diethyl-2-[(2-Trifluoromethylquinazolin-4-yl)oxy]ethan-1-Amine (48)

Yield $40 \%$. Colorless oil. ${ }^{1} \mathrm{H}$ NMR $\left(400 \mathrm{MHz} \mathrm{CDCl}_{3}\right) \delta=8.23(\mathrm{dd}, J=8.2,0.9 \mathrm{~Hz}, 1 \mathrm{H}), 8.07$ $(\mathrm{d}, J=8.4 \mathrm{~Hz}, 1 \mathrm{H}), 7.97-7.88(\mathrm{~m}, 1 \mathrm{H}), 7.72-7.65(\mathrm{~m}, 1 \mathrm{H}), 4.75(\mathrm{t}, \mathrm{J}=6.2 \mathrm{~Hz}, 2 \mathrm{H}), 3.00(\mathrm{t}, J=6.2 \mathrm{~Hz}, 2 \mathrm{H})$, 2.74-2.63 (m, 4H), 1.16-1.01 (m, 6H). $\left.{ }^{13} \mathrm{C} \mathrm{NMR} \mathrm{(101} \mathrm{MHz,} \mathrm{CDCl}_{3}\right) \delta 168.2,152.1(\mathrm{q}, J=36.4 \mathrm{~Hz}), 150.5$, $134.6,128.9,128.7,123.9,119.8(q, J=275.6 \mathrm{~Hz}), 116.8,66.6,50.9,48.1(2 \mathrm{C}), 12.2(2 \mathrm{C})$. LC-MS (ESI+) $t_{R} 2.84 \mathrm{~min}, m / z[\mathrm{M}+\mathrm{H}]^{+}$314.18. MW: $313.32 \mathrm{~g} / \mathrm{mol}$. HRMS $m / z[\mathrm{M}+\mathrm{H}]^{+}$calcd for $\mathrm{C}_{15} \mathrm{H}_{18} \mathrm{~F}_{3} \mathrm{~N}_{3} \mathrm{O}$ : 314.1475, Found: 314.1475 .

\subsubsection{N,N-Diethyl-2-(Quinazolin-4-yloxy)ethanamine (49)}

Yield 10\%. Yellow oil. ${ }^{1} \mathrm{H}$ NMR $\left(400 \mathrm{MHz} \mathrm{CDCl}_{3}\right) \delta=8.77(\mathrm{~s}, J=5.6 \mathrm{~Hz}, 1 \mathrm{H}), 8.18-8.05(\mathrm{~m}, 1 \mathrm{H})$, $7.90(\mathrm{~d}, J=8.4 \mathrm{~Hz}, 1 \mathrm{H}), 7.85-7.75(\mathrm{~m}, 1 \mathrm{H}), 7.59-7.44(\mathrm{~m}, 1 \mathrm{H}), 4.64(\mathrm{t}, J=6.1 \mathrm{~Hz}, 2 \mathrm{H}), 2.98(\mathrm{t}, J=6.1 \mathrm{~Hz}$, $2 \mathrm{H}), 2.66(\mathrm{q}, J=7.1 \mathrm{~Hz}, 4 \mathrm{H}), 1.08(\mathrm{t}, J=7.1 \mathrm{~Hz}, 6 \mathrm{H}) .{ }^{13} \mathrm{C} \mathrm{NMR}\left(101 \mathrm{MHz}, \mathrm{CDCl}_{3}\right) \delta=166.8,154.5,151.0$, 133.6, 127.7, 127.1, 123.6, 116.8, 65.6, 51.1, 47.9, 12.1. LC-MS (ESI+) $t_{R} 1.11 \mathrm{~min}, \mathrm{~m} / z$ [M + H] ${ }^{+} 246.21$. MW: $245.32 \mathrm{~g} / \mathrm{mol}$. Anal. Calcd for $\mathrm{C}_{14} \mathrm{H}_{19} \mathrm{~N}_{3} \mathrm{O}$ : C, 43.28; H, 2.54; N, 10.09. Found: C, 44.17; H, 3.14; $\mathrm{N}, 9.54$.

\subsection{Biology}

\subsubsection{In Vitro Cytotoxicity Evaluation}

HepG2 cell line was maintained at $37{ }^{\circ} \mathrm{C}, 5 \% \mathrm{CO}_{2}$, at $90 \%$ humidity in MEM supplemented with $10 \%$ fetal bovine serum, $1 \%$ L-glutamine $(200 \mathrm{mM})$ and penicillin $(100 \mathrm{U} / \mathrm{mL}) /$ streptomycin (100 $\mathrm{gg} / \mathrm{mL})$ (complete RPMI medium). The cytotoxicity of the tested molecules on the HepG2 (hepatocarcinoma cell line purchased from ATCC, ref HB-8065) cell line was assessed according to the method of Mosmann [19] with slight modifications. Briefly, $5.10^{3}$ cells in $100 \mu \mathrm{L}$ of complete medium were inoculated into each well of 96-well plates and incubated at $37^{\circ} \mathrm{C}$ in humidified $5 \% \mathrm{CO}_{2}$. After $24 \mathrm{~h}$ incubation, $100 \mu \mathrm{L}$ of medium with various product concentrations dissolved in DMSO (final concentration less than $0.5 \% \mathrm{v} / \mathrm{v}$ ) were added and the plates were incubated for $72 \mathrm{~h}$ at $37^{\circ} \mathrm{C}$. Triplicate assays were performed for each sample. Each plate-well was then microscope-examined for possible precipitate formation before the medium was aspirated from the wells. $100 \mu \mathrm{L}$ of MTT (3-(4,5-dimethyl-2-thiazolyl)-2,5-diphenyl-2H-tetrazolium bromide) solution $(0.5 \mathrm{mg} / \mathrm{mL}$ in medium without FBS) were then added to each well. Cells were incubated for $2 \mathrm{~h}$ at $37^{\circ} \mathrm{C}$. After this time, the MTT solution was removed and DMSO $(100 \mu \mathrm{L})$ was added to dissolve the resulting blue formazan crystals. Plates were shaken vigorously $(700 \mathrm{rpm})$ for $10 \mathrm{~min}$. The absorbance was measured at $570 \mathrm{~nm}$ with $630 \mathrm{~nm}$ as reference wavelength using a BIO-TEK ELx808 Absorbance Microplate Reader (LabX, Midland, ON, Canada). DMSO was used as blank and doxorubicin (purchased from Sigma Aldrich) as positive control. Cell viability was calculated as percentage of control (cells incubated without compound). The $50 \%$ cytotoxic concentration $\left(\mathrm{CC}_{50}\right)$ was determined from the dose-response curve, using TableCurve software $2 \mathrm{D}$ v.5.0. $\mathrm{CC}_{50}$ values represent the mean value calculated from three independent experiments. 


\subsubsection{In Vitro Antiplasmodial Evaluation}

In this study, a K1 culture-adapted P. falciparum strain resistant to chloroquine, pyrimethamine, and proguanil was used in an in vitro culture. It was maintained in continuous culture as described previously by Trager and Jensen [20]. Cultures were maintained in fresh A+ human erythrocytes at $2.5 \%$ hematocrit in complete medium (RPMI 1640 with $25 \mathrm{mM}$ HEPES, $25 \mathrm{mM} \mathrm{NaHCO}_{3}, 10 \%$ of $\mathrm{A}+$ human serum) at $37^{\circ} \mathrm{C}$ under reduced $\mathrm{O}_{2}$ atmosphere (gas mixture $10 \% \mathrm{O}_{2}, 5 \% \mathrm{CO}_{2}$, and $85 \% \mathrm{~N}_{2}$ ). Parasitemia was maintained daily at between 1 and 3\%. The P. falciparum drug susceptibility test was carried out by comparing quantities of DNA in treated and control cultures of parasite in human erythrocytes according to an SYBR Green I fluorescence-based method [21] using a 96-well fluorescence plate reader. Compounds, previously dissolved in DMSO (final concentration less than $0.5 \% v / v$ ), were incubated in a total assay volume of $200 \mu \mathrm{L}$ (RPMI, $2 \%$ hematocrit and $0.4 \%$ parasitemia) for $72 \mathrm{~h}$ in a humidified atmosphere $\left(10 \% \mathrm{O}_{2}\right.$ and $\left.5 \% \mathrm{CO}_{2}\right)$ at $37^{\circ} \mathrm{C}$, in 96-well flat bottom plates. Duplicate assays were performed for each sample. After incubation, plates were frozen at $-20^{\circ} \mathrm{C}$ for $24 \mathrm{~h}$. Then, the frozen plates were thawed for $1 \mathrm{~h}$ at $37^{\circ} \mathrm{C}$. Fifteen $\mu \mathrm{L}$ of each sample were transferred to 96 -well flat bottom non-sterile black plates (Greiner Bio-one) already containing $15 \mu \mathrm{L}$ of the SYBR Green I lysis buffer (2X SYBR Green I, $20 \mathrm{mM}$ Tris base pH 7.5, $20 \mathrm{mM}$ EDTA, 0.008\% w/v saponin, $0.08 \% \mathrm{w} / \mathrm{v}$ Triton X-100). Negative control treated by solvents (DMSO or $\mathrm{H}_{2} \mathrm{O}$ ) and positive controls (chloroquine and doxycycline) were added to each set of experiments. Plates were incubated for $15 \mathrm{~min}$ at $37^{\circ} \mathrm{C}$ and then read on a TECAN Infinite F-200 spectrophotometer with excitation and emission wavelengths at 485 and $535 \mathrm{~nm}$, respectively. The concentrations of compounds required to induce a 50\% decrease of parasite growth $\left(\mathrm{EC}_{50} \mathrm{~K} 1\right)$ were calculated from three independent experiments.

\section{Conclusions}

From previously identified antiplasmodial hit $\mathbf{C}$ and series $\mathbf{D}$ in 4-substituted-2trichloromethylquinazoline series, new derivatives were synthesized to explore the introduction of various 4-carboxamido or 4-alkoxy substituents. Thus, after screening reaction conditions to obtain carboxamide derivatives, 23 new molecules were obtained, including a dibenzamide. The four new hit molecules afforded are evidence that replacing a sulfonamido linker by a carboxamido one fosters antiplasmodial activity. In the second series, we obtained 19 new molecules bearing various alkoxy chains at position 4 . Two new hits were obtained, both bearing a tertiary amine function in the alkoxy chain, like chloroquine. For the more potent molecules in each series, the analogs prepared without the 2-trichloromethyl group showed that this group is essential to activity against $P$. falciparum. This work supports search for new derivatives centered on the 2-trichloromethylquinazoline scaffold.

Supplementary Materials: Figures S1-S29: 1H-NMR, 13C-NMR and HRMS data spectra of compounds 2, 9, 16, 24, 41, 44, 45, 46,48 and 49 .

Author Contributions: Funding acquisition, N.P.; investigation, D.A., A.G., S.H., and M.P.; methodology, D.A., A.G., S.H., and M.P.; supervision, P.V. (Pierre Verhaeghe), N.A., P.V. (Patrice Vanelle), and N.P.; writing—original draft, N.P.; writing - review and editing, P.V. (Patrice Vanelle) and N.P. All authors have read and agreed to the published version of the manuscript.

Funding: This research work was supported by a public grant of the French National Research Agency (Agence Nationale de la Recherche ANR), project NINTARMAL, grant number: ANR-17-CE11-0017.

Acknowledgments: Aix Marseille Université (AMU) and the Centre National de la Recherche Scientifique (CNRS) are gratefully acknowledged for financial support. The authors thank Gilles Lanzada for his help in organic synthesis and Vincent Remusat for the NMR spectra.

Conflicts of Interest: The authors declare no conflict of interest. 


\section{References}

1. World Health Organization (WHO). World Malaria Report 2019. Available online: https://www.who.int/ publications-detail-redirect/world-malaria-report-2019 (accessed on 30 June 2020).

2. Mbengue, A.; Bhattacharjee, S.; Pandharkar, T.; Liu, H.; Estiu, G.; Stahelin, R.V.; Rizk, S.S.; Njimoh, D.L.; Ryan, Y.; Chotivanich, K.; et al. Molecular Mechanism of Artemisinin Resistance in Plasmodium falciparum Malaria. Nature 2015, 520, 683-687. [CrossRef] [PubMed]

3. Müller, O.; Lu, G.Y.; von Seidlein, L. Geographic Expansion of Artemisinin Resistance. J. Travel Med. 2019, 26, taz030. [CrossRef] [PubMed]

4. Ocan, M.; Akena, D.; Nsobya, S.; Kamya, M.R.; Senono, R.; Kinengyere, A.A.; Obuku, E. K13-Propeller Gene Polymorphisms in Plasmodium falciparum Parasite Population in Malaria Affected Countries: A Systematic Review of Prevalence and Risk Factors. Malar. J. 2019, 18, 60. [CrossRef] [PubMed]

5. Kobayashi, S.; Ueno, M.; Suzuki, R.; Ishitani, H.; Kim, H.-S.; Wataya, Y. Catalytic Asymmetric Synthesis of Antimalarial Alkaloids Febrifugine and Isofebrifugine and Their Biological Activity. J. Org. Chem. 1999, 64, 6833-6841. [CrossRef] [PubMed]

6. Gellis, A.; Kieffer, C.; Primas, N.; Lanzada, G.; Giorgi, M.; Verhaeghe, P.; Vanelle, P. A New DMAP-Catalyzed and Microwave-Assisted Approach for Introducing Heteroarylamino Substituents at Position-4 of the Quinazoline Ring. Tetrahedron 2014, 70, 8257-8266. [CrossRef]

7. Cohen, A.; Suzanne, P.; Lancelot, J.-C.; Verhaeghe, P.; Lesnard, A.; Basmaciyan, L.; Hutter, S.; Laget, M.; Dumètre, A.; Paloque, L.; et al. Discovery of New Thienopyrimidinone Derivatives Displaying Antimalarial Properties toward Both Erythrocytic and Hepatic Stages of Plasmodium. Eur. J. Med. Chem. 2015, 95, 16-28. [CrossRef] [PubMed]

8. Desroches, J.; Kieffer, C.; Primas, N.; Hutter, S.; Gellis, A.; El-Kashef, H.; Rathelot, P.; Verhaeghe, P.; Azas, N.; Vanelle, P. Discovery of New Hit-Molecules Targeting Plasmodium falciparum through a Global SAR Study of the 4-Substituted-2-Trichloromethylquinazoline Antiplasmodial Scaffold. Eur. J. Med. Chem. 2017, 125, 68-86. [CrossRef] [PubMed]

9. Verhaeghe, P.; Azas, N.; Gasquet, M.; Hutter, S.; Ducros, C.; Laget, M.; Rault, S.; Rathelot, P.; Vanelle, P. Synthesis and Antiplasmodial Activity of New 4-Aryl-2-Trichloromethylquinazolines. Bioorg. Med. Chem. Lett. 2008, 18, 396-401. [CrossRef] [PubMed]

10. Castera-Ducros, C.; Azas, N.; Verhaeghe, P.; Hutter, S.; Garrigue, P.; Dumètre, A.; Mbatchi, L.; Laget, M.; Remusat, V.; Sifredi, F.; et al. Targeting the Human Malaria Parasite Plasmodium falciparum: In Vitro Identification of a New Antiplasmodial Hit in 4-Phenoxy-2-Trichloromethylquinazoline Series. Eur. J. Med. Chem. 2011, 46, 4184-4191. [CrossRef] [PubMed]

11. Gellis, A.; Primas, N.; Hutter, S.; Lanzada, G.; Remusat, V.; Verhaeghe, P.; Vanelle, P.; Azas, N. Looking for New Antiplasmodial Quinazolines: DMAP-Catalyzed Synthesis of 4-Benzyloxy- and 4-Aryloxy-2-Trichloromethylquinazolines and Their in Vitro Evaluation toward Plasmodium falciparum. Eur. J. Med. Chem. 2016, 119, 34-44. [CrossRef] [PubMed]

12. Primas, N.; Verhaeghe, P.; Cohen, A.; Kieffer, C.; Dumètre, A.; Hutter, S.; Rault, S.; Rathelot, P.; Azas, N.; Vanelle, P. A New Synthetic Route to Original Sulfonamide Derivatives in 2-Trichloromethylquinazoline Series: A Structure-Activity Relationship Study of Antiplasmodial Activity. Molecules 2012, 17, 8105-8117. [CrossRef] [PubMed]

13. Verhaeghe, P.; Rathelot, P.; Gellis, A.; Rault, S.; Vanelle, P. Highly Efficient Microwave Assisted $\alpha$-Trichlorination Reaction of $\alpha$-Methylated Nitrogen Containing Heterocycles. Tetrahedron 2006, 62, 8173-8176. [CrossRef]

14. Verhaeghe, P.; Azas, N.; Hutter, S.; Castera-Ducros, C.; Laget, M.; Dumètre, A.; Gasquet, M.; Reboul, J.-P.; Rault, S.; Rathelot, P.; et al. Synthesis and in Vitro Antiplasmodial Evaluation of 4-Anilino2-Trichloromethylquinazolines. Bioorg. Med. Chem. 2009, 17, 4313-4322. [CrossRef] [PubMed]

15. Verhaeghe, P.; Dumètre, A.; Castera-Ducros, C.; Hutter, S.; Laget, M.; Fersing, C.; Prieri, M.; Yzombard, J.; Sifredi, F.; Rault, S.; et al. 4-Thiophenoxy-2-Trichloromethyquinazolines Display in Vitro Selective Antiplasmodial Activity against the Human Malaria Parasite Plasmodium falciparum. Bioorg. Med. Chem. Lett. 2011, 21, 6003-6006. [CrossRef] [PubMed]

16. Stumpfe, D.; Bajorath, J. Exploring Activity Cliffs in Medicinal Chemistry. J. Med. Chem. 2012, 55, $2932-2942$. [CrossRef] [PubMed] 
17. Caballero-García, G.; Romero-Ortega, M.; Barroso-Flores, J. Reactivity of Electrophilic Chlorine Atoms Due to $\sigma$-Holes: A Mechanistic Assessment of the Chemical Reduction of a Trichloromethyl Group by Sulfur Nucleophiles. Phys. Chem. Chem. Phys. 2016, 18, 27300-27307. [CrossRef] [PubMed]

18. Rosenthal, P.J. Falcipain Cysteine Proteases of Malaria Parasites: An Update. Biochim. Biophys. Acta Proteins Proteom. 2020, 1868, 140362. [CrossRef] [PubMed]

19. Mosmann, T. Rapid Colorimetric Assay for Cellular Growth and Survival: Application to Proliferation and Cytotoxicity Assays. J. Immunol. Methods 1983, 65, 55-63. [CrossRef]

20. Trager, W.; Jensen, J.B. Human Malaria Parasites in Continuous Culture. Science 1976, 193, 673-675. [CrossRef] [PubMed]

21. Guiguemde, W.A.; Shelat, A.A.; Bouck, D.; Duffy, S.; Crowther, G.J.; Davis, P.H.; Smithson, D.C.; Connelly, M.; Clark, J.; Zhu, F.; et al. Chemical Genetics of Plasmodium falciparum. Nature 2010, 465, 311-315. [CrossRef] [PubMed]

Sample Availability: Samples of the compounds 2, 9, 16, 24, 41 and 44 are available from the authors.

(C) 2020 by the authors. Licensee MDPI, Basel, Switzerland. This article is an open access article distributed under the terms and conditions of the Creative Commons Attribution (CC BY) license (http://creativecommons.org/licenses/by/4.0/). 